\title{
De nuevo sobre el nivel intermedio de gobierno local. ¿Qué cabe hacer sin reformar la Constitución?
}

\section{Expanding on the intermediate level of local government. What could be done without reforming the Constitution?}

\author{
Concepción Barrero Rodríguez \\ Universidad de Sevilla (España) \\ ORCID: https://orcid.org/0000-0002-5500-8662 \\ barrero@us.es
}

\section{NOTA BIOGRÁFICA}

Catedrática de Derecho Administrativo de la Universidad de Sevilla. Entre sus líneas de investigación se encuentran la contratación pública, el procedimiento administrativo, el régimen local, el Derecho de la transparencia pública o la ordenación del Patrimonio Histórico.

\section{RESUMEN}

Este estudio expone la situación actual de la organización supramunicipal y reflexiona sobre la conveniencia de su reforma y el posible alcance y sentido de esta.

\section{PALABRAS CLAVE}

Organización supramunicipal; provincia; comarca; áreas metropolitanas; mancomunidad de municipios.

\section{ABSTRACT}

This study presents the current state of the supramunicipal organization and reflects on the convenience of its reform and the potential scope and meaning of it.

\section{KEYWORDS}

Supramunicipal organization; province; district; metropolitan areas; municipality of municipalities.

\section{SUMARIO}

I. CONSIDERACIONES INICIALES. II. EL GOBIERNO LOCAL SUPRAMUNICIPAL EN EL ORDENAMIENTO VIGENTE. 1. LA PROVINCIA EN LA LEY BÁSICA DE RÉGIMEN LOCAL: ¿UNA REGULACIÓN INSUFICIENTE DE LA INSTANCIA SUPRAMUNICIPAL OBLIGADA POR LA CONSTITUCIÓN? 2. LA ORGANIZACIÓN SUPRAMUNICIPAL PARALELAA LA PROVINCIAL. SU DESARROLLO POR EL ORDENAMIENTO AUTONÓMICO. 2.1. La entidad comarcal. 2.2. Las áreas metropolitanas. 2.3. Las mancomunidades de municipios. 3. Algunas ideas conclusivas. III. UNA REFORMA NECESARIA, QUÉ REFORMA ES POSIBLE. REFERENCIAS BIBLIOGRÁFICAS. 


\section{CONSIDERACIONES INICIALES}

Cuarenta años de vigencia de la Constitución de 1978 no han servido para la articulación de un nivel de gobierno local supramunicipal que satisfaga las demandas tanto de la «España vaciada» ${ }^{1}$, como de esa otra que se concentra en los poblados núcleos urbanos del litoral y algunos enclaves interiores. La garantía de unos servicios públicos de calidad en todo el territorio del Estado sigue constituyendo uno de los grandes retos del Derecho y de la acción pública en nuestros días. Un desafío, desde luego, en esos 5.002 municipios, de los 8.131 existentes, que, de acuerdo con los datos ofrecidos por el Instituto Nacional de Estadística referidos al 1 de enero de 2019, tienen menos de 1.000 habitantes $^{2}$; pero un hándicap también en las grandes áreas urbanas que evidencian igualmente la conveniencia de superar el término municipal en beneficio de espacios más amplios que permitan una gestión conjunta de los servicios que así lo requieran en coordinación, en su caso, con el conjunto de políticas públicas que se desarrollen en el territorio.

El ordenamiento dictado en desarrollo de la Constitución de 1978 es, desde luego, consciente de la necesidad de dar respuesta a los intereses propios de los espacios supramunicipales y en la literatura jurídica de los últimos años abundan estudios que analizan el tratamiento que las normas les dispensan y efectúan, en su caso, propuestas de lege ferenda que puedan contribuir a la mejor ordenación de un nivel de gobierno que, a pesar del tiempo transcurrido desde la promulgación de la norma fundamental, no parece, si nos atenemos a los juicios que sobre él se han vertido -la Fundación Democracia y Gobierno Local lo consideró «desarticulado, asimétrico y escasamente eficiente, cuando no claramente disfuncional» ${ }^{3}-$, que haya logrado un mínimo nivel de aceptación no ya jurídica, sino, incluso, política y social. Resulta pues obligado seguir reflexionando sobre el tema aun cuando pueda parecer que todo está ya dicho, que poco puede aportarse a lo mucho escrito desde la promulgación de la Ley $7 / 1985$, de 2 de abril, reguladora de las Bases del Régimen Local (LBRL) y el ordenamiento autonómico que le sigue. No voy pues a detenerme en el análisis detallado de las diferentes entidades que conforman este nivel territorial de gobierno, me propongo simplemente efectuar algunas consideraciones sobre qué ha podido, en su caso, fallar en ese Derecho a partir de la exposición de sus notas más características, para concluir con unas reflexiones finales sobre aquellas líneas por las que pudiera avanzar una reforma, sin duda necesaria, pero, hasta ahora, fracasada.

\section{EL GOBIERNO LOCAL SUPRAMUNICIPAL EN EL ORDENAMIENTO VIGENTE}

Es ocioso manifestar a estas alturas que, como expresara M. F. CLAVERO ARÉVALO, «nuestra Constitución es provincialista ${ }^{4}$, apuesta, tras no pocas dudas iniciales ${ }^{5}$ y en un contexto de amplio cuestionamiento de la institución ${ }^{6}$, por el mantenimiento de la provincia, al margen de su condición de «división territorial

1 La Coordinadora de la «España Vaciada», constituida recientemente por más de treinta colectivos de diferentes lugares de España, liderados por las plataformas «Soria Ya» y «Teruel Existe», reivindicaba, en el manifiesto por ejemplo efectuado en el paro convocado el 4 de octubre de 2019, «un verdadero Pacto de Estado contra la despoblación, contra la desvertebración territorial de España y contra la creciente desigualdad de oportunidades entre ciudadanos españoles». El verano de ese mismo año, según noticias aparecidas en prensa, había solicitado la creación de un Ministerio, o al menos de una Secretaría de Estado, sobre Repoblación.

2 De ellos, y según datos del Registro de Entidades Locales del Ministerio de Política Territorial referenciados a 2010 aunque los cambios no han sido significativos, 2.236 tienen entre 250 y 1.000 habitantes, 1.074 cuentan con menos de 100 .

La literatura jurídica se ha referido ampliamente a los problemas que estos municipios encuentran a la hora de gestionar sus competencias. Así, y entre otros, puede verse estudio J. GIFREU I FONT, "La atomización de la planta municipal y sus repercusiones en la prestación eficiente de los servicios mínimos obligatorios: la operatividad de la función coordinadora de las diputaciones provinciales", L. PAREJO ALFONSO (dir.) y A. ARROYO GIL (coord.): El futuro de la Administración local y el papel de los Gobiernos locales intermedios, págs. 131-214, 2017, Madrid: Fundación Democracia y Gobierno Local.

3 "Libro verde. Los Gobiernos locales intermedios en España. Diagnóstico y propuestas para reforzar el valor institucional de las diputaciones provinciales y de los demás gobiernos locales intermedios en el Estado autonómico, pág. 76, 2011, Fundación Democracia y Gobierno Local.

4 "La Provincia ante una encrucijada histórica en el ciento cincuenta aniversario de su creación (1833-1893)", La Provincia: IX Congreso Italo-Español de Profesores de Derecho Administrativo, pág. 245, 1985, Granada: Departamento de Derecho Administrativo de la Universidad de Granada.

5 Como dejara expuesto L. LÓPEZ RODO (“La Provincia en las Comunidades Autónomas uniprovinciales y en Canarias”, La Provincia: IX Congreso Italo-Español de Profesores de Derecho Administrativo, op. cit., págs. 395-403) o M. ${ }^{a}$ CARBALLEIRA RIVERA (La provincia en el sistema autonómico español, págs. 23-75, 1993, Madrid: Marcial Pons).

6 En tal sentido, S. MARTÍN-RETORTILLO, "Introducción" a la obra recopilatoria de trabajos suyos en la materia, La provincia. Pasado, presente y futuro, pág. 18, 1991, Madrid: Civitas. 
para el cumplimiento de las actividades del Estado» y «circunscripción electoral», como «entidad local con personalidad jurídica propia, determinada por la agrupación de municipios» y dotada «de autonomía para la gestión de sus respectivos intereses». Ahora bien, la Constitución de 1978 no solo instituye un nivel supramunicipal de gobierno, el provincial, sino que en sus artículos 141.3 y 152.3 abre además la puerta a otras posibles entidades surgidas de "agrupaciones de municipios diferentes de la provincia», permite que los Estatutos de Autonomía puedan «establecer circunscripciones territoriales propias, que gozarán de plena personalidad jurídica» mediante «la agrupación de municipios limítrofes». Aunque no se ofrecen más detalles sobre las mismas, es claro que estamos ante entidades de naturaleza coincidente con la provincial con la que, en consecuencia, comparten un mismo nivel de gobierno, el supramunicipal, toda vez que no parecía, y así vino además a refrendarlo el Tribunal Constitución, que la creación por las Comunidades Autónomas de «circunscripciones territoriales propias» pudiera ser en sustitución de la instancia provincial. De esta forma, la Constitución al apostar, de la mano de las provincias, por una uniformidad del nivel supramunicipal de gobierno en todo el territorio y, al propio tiempo, por la diversidad surgida de las distintas opciones autonómicas plasmadas en sus Estatutos, hace muy difícil una articulación racional de este nivel de gobierno. El propio Consejo de Estado advertía en su dictamen 1/2005, de 16 de febrero de 2006, sobre la reforma constitucional, sobre cómo en la norma fundamental no existe "guía alguna para establecer cuál debe ser la relación» entre las provincias y los demás entes que a su amparo puedan crearse. Veamos la respuesta que, hasta ahora, ha ofrecido el ordenamiento dictado en su desarrollo.

\section{La provincia en la Ley básica de régimen local: ¿Una regulación insuficiente de la instancia supramunicipal obligada por la Constitución?}

La constitucionalización de la provincia no ha ido acompañada, como sabemos, de la fijación, entre otros extremos, del cometido propio de este nivel de gobierno, más allá de esa genérica alusión a «la gestión de sus respectivos intereses». En manos del legislador ordinario quedó pues el diseño de la entidad encargada de su gobierno y administración, la diputación, en sus aspectos tanto organizativos como competenciales a partir de esos intereses de obligada concreción. La norma fundamental -es importante tenerlo en cuenta-, no prejuzga la naturaleza de las competencias provinciales y ni, mucho menos, decide cuáles hayan de ser los territorios objeto de una atención prioritaria por su parte ${ }^{7}$. Será la LBRL en 1985 la que, fracasados los intentos de convertir a la provincia en ente para el ejercicio de las competencias de la Administración autonómica ${ }^{8}$, se decante por una entidad local con competencias fundamentalmente de apoyo a los municipios en el contexto de una planta local caracterizada por el elevado número de municipios con umbrales muy bajos de población. «Asegurar la prestación integral y adecuada en la totalidad del territorio provincial de los servicios de competencia municipal» se convierte así, en su artículo 31.2, en el fin básico que justifica y explica el conjunto de competencias de marcado carácter funcional que el artículo 36.1 atribuye a las diputaciones. Además, el Tribunal Constitucional en su Sentencia 109/1988, de 21 de mayo y, más tarde en la 111/2016, de 9 de junio, va a identificar con la competencia de «asistencia y cooperación jurídica, económica y técnica a los Municipios, especialmente los de menor capacidad económica y de gestión», conferida a las diputaciones por la letra b) del precepto, «el núcleo esencial de la autonomía provincial», su «ámbito material diferenciado», dejando planteada la duda de si el resto de las establecidas en el precepto «integran también el núcleo cuyo menoscabo merezca reproche de inconstitucionalidad» ${ }^{9}$. Sea como sea, lo cierto es que la asistencia y apoyo a los municipios centrará, desde esos momentos, el núcleo básico de la actividad provincial en detrimento del resto de las competencias previstas en el propio artículo 36.1, como

7 L. PAREJO ALFONSO, entre otros autores, ha reflexionado sobre los condicionantes derivados de la Constitución para la configuración de la provincia por el legislador ordinario, destacando su condición de gestora de intereses «referibles a su condición de agrupación de municipios, es decir, escapen a, o desborden, el círculo de los que corresponde gestionar a cada uno de estos por separado (sin por ello deber ser incluidos en los gestionados por las instancias territoriales superiores: autonómica y estatal strictu sensu)» ("Algunas reflexiones sobre posibles líneas maestras de arreglo de la provincia y la diputación peninsulares de régimen común", en la obra por él dirigida El futuro de la Administración local y el papel de los Gobiernos locales intermedios, op. cit., pág. 17).

8 Véase Informe de la Comisión de expertos sobre Autonomías, 1981, Madrid: Centro de Estudios Constitucionales.

9 M. ZAFRA VÍCTOR, "La provincia: lo importante no es el nombre, lo importante es la función. Intermunicipalidad en el Estado autonómico", El Cronista del Estado Social y Democrático de Derecho, núm. 27, marzo 2012, pág. 73.

J. L. CARRO FERNÁNDEZ-VALMAYOR, en tiempos más recientes, se ha sumado a las críticas a esa jurisprudencia que reduce la garantía institucional de la provincia «a una simple actuación cooperadora con los Municipios», al considerarla «limitadora de la función que la propia Constitución le atribuye de "gobierno y administración autónoma" de su ámbito territorial» ("Articulación organizativa y Estado compuesto", Documentación Administrativa (DA), núm. 3, 2016, págs. 6 y 7). 
la prestación de servicios supramunicipales o, incluso, la misma cláusula general contenida en su letra d). El ordenamiento de las Comunidades Autónomas consolidará definitivamente un modelo de diputación articulado sobre la base del auxilio y cooperación con los municipios ${ }^{10}$, del que resulta fácil concluir que su ámbito natural de actuación queda determinado por los pequeños municipios, «los de menor capacidad económica y de gestión», concepción que, a su vez, hallará el respaldo de una doctrina que no dudará en resaltar el papel de la provincia «como municipio de municipios incompletos por dimensión-capacidad insuficiente» ${ }^{11}$, una institución cuya singularidad radica en «hacer posible la viabilidad política de un municipalismo inarticulado, poco poblado y con escasa capacidad de gestión» ${ }^{12}$.

La decantación legal, que no constitucional, por una provincia de «marcada vocación ruralista» en expresión de S. MARTÍN-RETORTILLO ${ }^{13}$, trae consigo dos consecuencias, al menos, en las que quizás no se haya reparado en su justa medida pero que contribuyen a explicar la situación de la supramunicipalidad en España y siguen constituyendo cuestiones pendientes. De una parte, la indefinición en la que queda el cometido de las diputaciones, si es que han de tener alguno, respecto de aquellos municipios, que son también muchos, capacitados, en principio, para el ejercicio de sus competencias y en los que la conveniencia, en su caso, de la intervención de un ente supramunicipal no deriva de una insuficiencia basada en razones de índole fundamentalmente económica, sino de la garantía de principios como los de eficacia, eficiencia y coordinación en áreas de gran población en las que los términos municipales son de facto irreconocibles. Habrá que esperar muchos años tras la promulgación de la Constitución y la LBRL para que autores como L. PAREJO o la propia Federación Española de Municipios y Provincias (FEMP) se hagan eco de la cuestión, apuntando la posibilidad, opción que habría que valorar desde el punto de vista constitucional -implica considerar que no todos los municipios han de estar integrados en una provincia ${ }^{14}$-, de que tales municipios queden «liberados» del «vínculo de la agrupación». Desde posiciones contrarias, se llamará, sin embargo, la atención, así lo hizo la declaración institucional de la Il Conferencia de Presidentes de Gobiernos Provinciales, celebrada en Badajoz en noviembre de 2016, sobre la necesidad de una reformulación de las competencias provinciales acorde «con las demandas de los ciudadanos que residen en el mundo rural» pero también «de los que lo hacen en zonas más pobladas pero necesitadas de colaboración supramunicipal» ${ }^{15}$. Desde luego, el futuro de la supramunicipalidad en España, el futuro de las propias diputaciones, pasa por la definición de su papel fuera de esos pequeños municipios incapaces por sí mismos de cumplir con las competencias que la Ley les impone,

10 T. DE LA CUADRA SALCEDO ha reflexionado, no obstante, sobre los importantes fines que, a través de ella, satisfacen las diputaciones ("El debate sobre las diputaciones en un escenario de reforma constitucional del Título VIII", Documentación Administrativa (DA), núm. 3, 2016, págs. 7-10).

11 L. PAREJO ALFONSO, "Apuntes para el debate sobre la planta y la articulación interna de la Administración local”, Cuadernos de Derecho Local (QDL), núm. 29, 2012, pág. 20.

12 M. ZAFRA VÍCTOR, "Relaciones entre municipios y provincias", Cuadernos de Derecho Local (QDL), núm. 29, 2012, pág. 120.

13 La provincia. Pasado, presente y futuro, op. cit., pág. 81.

14 Así lo viene manteniendo L. PAREJO que considera, en efecto, que el marco constitucional «no exige que la agrupación constitutiva de la provincia incluya todos los municipios. La provincia es, sencillamente, "agrupación de municipios". Lo que hace posible hasta la importación de la fórmula alemana de la "liberación" (de la agrupación) de ciertos municipios». Avanzando en esta idea, propone «atendiendo a las tendencias de reforma territorial observables en los países de nuestro entorno inmediato y a la evolución del proceso de urbanización en la península» situar en los 50.000 habitantes el umbral en el que un municipio dejaría de pertenecer a la diputación, lo que afectaría a algo menos de 400 ("Algunas reflexiones sobre posibles líneas maestras de arreglo de la provincia y la diputación peninsulares de régimen común”, op. cit., págs. 18 y 28). Ya en un trabajo anterior había defendido esa posibilidad de que los municipios suficientes para la prestación de sus competencias puedan quedar «liberados» del «vínculo de la agrupación», es decir, «no "pertenecerían" a la Diputación, y quedarían fuera de su radio de acción y, por tanto, de su cometido propio» ("Apuntes para el debate sobre la planta y la articulación interna de la Administración local”, op. cit., pág. 20), tesis defendida, más tarde, en "El porvenir a la luz de los condicionantes de la actual coyuntura, del escalón supramunicipal de la Administración local” (Cuadernos de Derecho Local (QDL), núm. 40, 2016, pág. 28) y “¿Tiene futuro la provincia como entidad local intermedia?” (Revista Democracia y Gobierno Local, núm. 34, 2016, pág. 5, pág. 9). J. L. CARRO se ha hecho eco de esta «interesante propuesta» que «significaría, naturalmente, la pérdida de la caracterización de la Provincia como agrupación necesaria de la "totalidad" de los Municipios; exigencia de totalidad a la que, sin embargo, no se alude en la Constitución española» (“Articulación organizativa y Estado compuesto”, op. cit., núm. 3, 2016, pág. 9). G. FERNÁNDEZ FARRERES, sin embargo, ha expresado sus dudas sobre la misma ("Qué hacer con las diputaciones provinciales (Presupuestos y límites constitucionales para su reforma)", El futuro de la Administración local y el papel de los Gobiernos locales intermedios, op. cit., págs. 99-100).

En una línea similar a la de L. PAREJO, la FEMP en su "Informe sobre competencias de las corporaciones locales", de abril de 2012, manifestó que «el ámbito de actuación de las Diputaciones, Cabildos y Consejos como administración común de los municipios debería limitarse a aquellos que carezcan de los medios técnicos y/o económicos necesarios para prestar los servicios y realizar las actividades que se deriven de sus competencias».

15 Declaración recogida en el número 35 de 2016 de la Revista Democracia y Gobierno local, págs. 27-31. 
por más que no quepa negar la relevancia de su actuación en estos territorios. Ahora bien, no parece sencillamente lógico que de la acción de una entidad que agrupa hoy a todos los municipios españoles queden, de hecho, al margen buena parte de los mismos. Es preciso pues, lo que hasta ahora no se ha hecho, definir su papel en estos casos.

El triunfo de un modelo de diputación fundado en el apoyo a los municipios de menor capacidad económica y de gestión trae además consigo -y esta es la segunda idea sobre la que debe llamarse la atenciónel que, como se ha dicho, se haya «enquistado la posibilidad (no cerrada constitucionalmente) de que las provincias dispongan de competencias materiales propias» ${ }^{16}$. En efecto, tanto la LBRL como, más tarde, el ordenamiento autonómico podrían perfectamente haber completado esas funciones de cooperación con los municipios con competencias sustantivas surgidas de una identificación de los «intereses provinciales» que han de satisfacer. Esta falta de definición de un ámbito competencial propio en favor de las diputaciones tiene probablemente mucho que ver con los intentos de desplazamiento del que de facto han sido objeto por parte de otras entidades y contribuye quizás a explicar el propio cuestionamiento de la instancia provincial al que hemos asistido en los últimos años. En la actualidad, cualquier debate sobre el nivel intermedio de gobierno local debe pues decidir para qué se desea que sirvan las diputaciones, si solo para hacer frente a problemas de insuficiencia municipal o, también, para desarrollar otras competencias del interés de sus respectivos territorios.

La configuración de la provincia en la Ley de 1985 no solo no es corregida por el ordenamiento posterior, sino que se ve acentuada. En efecto, la LRSAL -las anteriores reformas de la LBRL apenas afectan a esta instancia ${ }^{17}$ - consolida el papel de las diputaciones al servicio de los pequeños municipios ${ }^{18}$. No de otra forma puede valorarse la reforma del artículo 26 a fin de que las diputaciones puedan asumir la prestación de los servicios de los municipios de menos de 20.000 habitantes. Aunque la modificación legal de 2013 alcanza a las competencias provinciales definidas en el artículo $36^{19}$-reforma, no obstante, «más aparente que real» ${ }^{20}$, pues las competencias funcionales que ahora se les asignan «no difieren tanto» de las que ya tenían ${ }^{21}$-, es, sin embargo, el nuevo artículo 26.2 el que viene con precisión a dar cuenta de cómo para el legislador la función primordial de las diputaciones no es otra que la de garantizar la prestación de los servicios en los municipios que por contar con una población inferior a 20.000 habitantes, la propia Ley presume que pueden necesitar del auxilio de la diputación. El contenido del precepto ha sido ya suficientemente analizado por la doctrina ${ }^{22}$. Recordemos sencillamente que dispone que «será la Diputación provincial o entidad equivalente la que coordinará la prestación» de los servicios en tales municipios, para lo cual propondrá, «con la conformidad de los municipios afectados, al Ministerio de Hacienda y Administraciones Públicas la forma de prestación, consistente en la prestación directa por la Diputación o la implantación de fórmulas de gestión compartida a través de consorcios, mancomunidades u otras fórmulas. Para reducir los costes efectivos de los servicios el mencionado Ministerio decidirá sobre la propuesta formulada que deberá contar con el informe preceptivo de la Comunidad Autónoma si es la Administración que ejerce la tutela financiera». En esta norma, muy defectuosa técnicamente, destaca, frente a lo dis-

16 Libro verde. Los Gobiernos locales intermedios en España, op. cit., pág. 67.

17 En efecto, no lo hizo la Ley 11/1999, de 13 de abril, lo que, como manifestara P. ESCRIBANO COLLADO, lleva a pensar que «para el legislador estatal las diputaciones no debían ser reformadas y, si convenía hacerlo, no se sabía cómo» ("Provincias y diputaciones: Una polémica sin proyecto institucional”, J. M. BAÑO LEON (coord.), Memorial para la reforma del Estado. Estudios en homenaje al profesor Santiago Muñoz Machado, vol. II, pág. 2.006, 2016, Madrid: Centro de Estudios Políticos y Constitucionales) y las modificaciones, de otra parte, introducidas por la Ley 57/2003, de Medidas para la Modernización del Gobierno Local, en el ámbito competencial de la entidad no pueden considerarse relevantes.

18 Al respecto pueden verse las consideraciones de M. SALVADOR CRESPO, "El papel de los gobiernos locales intermedios en la actualidad", Revista Democracia y Gobierno Local, núm. 44, 2019, págs. 10-11.

19 Así se amplía la prestación de servicios supramunicipales y se suprime la competencia de «fomento y administración de los intereses peculiares de la provincia». Por lo demás, las diputaciones podrán seguir contando con las competencias que puedan delegarles las Comunidades Autónomas y con aquellas «distintas de las propias y de las atribuidas por delegación» previstas en el nuevo artículo 7.4 de la LBRL. Finalmente se mantiene la posibilidad, en contra de una realidad en la que se han impuesto otras soluciones, de que las diputaciones asuman «la gestión ordinaria de servicios propios» de la Comunidad Autónoma.

20 E. CARBONELL PORRAS, "Replanteamiento sobre las provincias: del pretendido reforzamiento de su posición institucional a una posible mutación constitucional”, Anuario del Gobierno Local 2015/2016, págs. 124-125, 2016, Fundación Democracia y Gobierno Local.

21 M. SALVADOR CRESPO, "Las competencias de las diputaciones provinciales en la Ley 27/2013, de 27 de diciembre, de Racionalización y sostenibilidad de la Administración local”, Cuadernos de Derecho Local (QDL), núm. 34, 2014, pág. 135.

22 Yo misma lo hice en "La prestación de los servicios municipales mínimos en el nuevo artículo 26 de la LBRL. La difícil interpretación de un precepto fundamental”, Revista Española de Derecho Administrativo, núm. 170, 2015, págs. 21 y ss. 
puesto en las primeras versiones del Anteproyecto de Ley que conocimos $^{23}$, la necesaria «conformidad» de los municipios con la «forma de prestación» de los servicios propuesta por la diputación, requisito que permitirá a la STC 111/2016, de 9 de junio, declarar su constitucionalidad por no resultar así lesiva de «la garantía consagrada en los artículos 137 y 141 CE». En realidad, las funciones de la diputación, en la calificación que le otorga la Nota explicativa de la reforma local de 29 de abril de 2016 del entonces Ministerio de Hacienda y Administraciones Públicas, quedan reducidas a las de «mera propuesta e impulso». De otra parte, debe de llamarse la atención sobre la atribución de la competencia para resolver a la Administración del Estado que el Tribunal Constitucional, sin embargo, sí va a estimar contraria a la Constitución al no encontrar apoyo ni en su artículo 149.1.18, ni en competencias sectoriales sobre los distintos servicios del artículo 26.2 de la LBRL. Finalmente, cabe notar que la aplicación del precepto queda subordinada a la determinación del coste efectivo de los servicios públicos regulado en el nuevo artículo 116 ter de la LBRL cuyo desarrollo reglamentario se produjo en el año siguiente ${ }^{24}$, aunque no parece que haya servido para disponer de datos actualizados sobre ese coste en los diferentes municipios ${ }^{25} \mathrm{y}$ todo apunta, como anticipara J. A. SANTAMARÍA, a que no se están dando los pasos necesarios por parte de las diferentes entidades implicadas en pro de hallar la fórmula de gestión conjunta de los servicios municipales ${ }^{26}$.

En conclusión, la provincia, instancia supramunicipal necesaria en todo el territorio del Estado por mandato constitucional, ve prácticamente reducido su papel en la legislación básica de régimen local al de una entidad de apoyo, de cooperación económica y técnica con los municipios de menor capacidad, dado, por lo general, sus bajos niveles de población. La opción legal escogida deja además en la indefinición el papel de la diputación, si es que ha de tener alguno, respecto de aquellos municipios suficientes, en principio, para prestar las competencias que la norma les impone. Dos datos que contribuyen de forma decisiva a explicar el actual panorama de la supramunicipalidad en España.

\section{La organización supramunicipal paralela a la provincial. Su desarrollo por el ordenamiento autonómico}

La LBRL, atenta a los mandatos constitucionales que permiten la creación de instancias supramunicipales distintas de la provincia, prevé en su artículo 3.2 y regula en su Título IV "otras entidades locales»: las comarcas, las áreas metropolitanas y las mancomunidades de municipios. Ahora bien, se trata, como las calificó el Tribunal Constitucional en su Sentencia 214/1989, de 21 de diciembre, de entidades con «un fuerte grado de interiorización autonómica», pues entran «en cuanto a su propia existencia, en el ámbito de disponibilidad de las Comunidades Autónomas que dispongan de la correspondiente competencia». A ellas les compete además «determinar y fijar las competencias de las Entidades locales que procedan a crear en sus respectivos ámbitos territoriales» ${ }^{27}$, dentro del respeto, como afirmó el Tribunal en esa sentencia y, de nuevo, en la 41/2016, de 3 de marzo, al marco básico estatal. Ahora bien, más que adentrarnos en disquisiciones sobre el alcance de la competencia estatal respecto de estas entidades, interesa hacer balance sobre cuál ha sido su desarrollo durante el ya largo periodo histórico de vigencia de la Constitución de 1978 y del ordenamiento local surgido de ella, con la atención puesta en aquello para lo que lo sirven, en la función que han de desarrollar. Otras cuestiones, sin duda importantes, como las relativas a su organización o su forma de constitución, permanecen, por tanto, al margen de nuestra atención. Antes de adentrarnos en el análisis de cada entidad, cabe, con carácter general, dejar constancia del escaso arraigo, salvo en determinados territorios, de comarcas y áreas metropolitanas, frente a la gran implantación, por el contrario, de las mancomunidades de municipios que han experimentado un extraordinario desarrollo en el conjunto del Estado bajo el impulso decidido del ordenamiento autonómico.

23 En efecto, la intención originaria del Gobierno no era otra que la de la asunción directa por las diputaciones de la prestación de los servicios de los municipios de menos de 20.000 habitantes cuando estos no cumplieran con el coste estándar que el propio Gobierno había de regular. Una propuesta que suscitaba reparos importantes que el propio Consejo de Estado se encargó de advertir en su Dictamen 567/2013 y que propiciaron, sin duda, que en el Proyecto de Ley, en términos que se convertirán en Ley, el precepto apareciera sustancialmente reformado.

24 Así por la Orden 2075, de 6 de noviembre de 2014, del Ministerio de Hacienda y Administraciones Públicas y la Resolución de la Secretaría General de Coordinación Autonómica y Local de 23 de junio de 2015. Esa Orden obligaba a los municipios a facilitar, por vez primera, el coste de sus servicios antes del 1 de noviembre de 2015.

25 Los datos que ofrece la página web del Ministerio de Hacienda en octubre de 2019, hacen referencia al año 2013.

26 "El régimen de competencias locales y el dilema de la esfinge", J. A. SANTAMARÍA PASTOR (coord.), La reforma de 2013 del régimen local español, pág. 147, 2014, Madrid: Fundación Democracia y Gobierno Local.

27 Fundamentos Jurídicos $4 .^{\circ}$ y $13 .^{\circ}$. 


\subsection{La entidad comarcal}

La comarca, definida por el artículo 42.1 de la LBRL como entidad que agrupa «varios Municipios, cuyas características determinen intereses comunes precisados de una gestión propia o demanden la prestación de servicios de dicho ámbito", ha encontrado un amplio respaldo en los Estatutos de Autonomía dado que son mayoría las Comunidades Autónomas que prevén en su norma institucional básica este nivel de gobierno del territorio ${ }^{28}$. Ahora bien, son pocas, sin embargo, las que han procedido a su efectiva constitución, dado que solo Cataluña y Aragón han comarcalizado sus territorios, en tanto que Castilla y León ha creado una sola entidad de esta naturaleza, la de Bierzo, en respuesta a las necesidades concretas del espacio en el que se asienta. Aunque la norma estatal no se pronuncia expresamente sobre la naturaleza de la comarca, de su misma definición, así como de las garantías previstas en el propio artículo 42: creación por Ley y prohibición de que su constitución pueda suponer «la pérdida por los Municipios de la competencia para prestar los servicios enumerados en el artículo 26» o «todo tipo de intervención en las materias enumeradas en el apartado 2 del artículo $25 »$, cabe inferir su condición de ente territorial ${ }^{29}$, confirmada por las pocas disposiciones autonómicas que regulan entidades de esta naturaleza que apuestan, en efecto, por una Administración dotada de competencias múltiples y heterogéneas y de un amplio conjunto de potestades públicas.

El análisis de las Leyes autonómicas sobre comarcas permite, en efecto, comprobar el carácter amplio de sus competencias con un doble origen posible. De una parte, dichas normas disponen la participación de la entidad, en los términos que disponga el legislador sectorial, en materias inicialmente atribuidas a las Comunidades Autónomas que, como ocurre en la disposición catalana, no se determinan ${ }^{30}$, o que, como en el caso de la comarca del Bierzo, quedan establecidas en la propia norma que regula la entidad ${ }^{31}$. La disposición aragonesa da un paso más y determina el alcance y modo de intervención de la comarca en los distintos sectores de la actividad en los que prevé su participación ${ }^{32 y}{ }^{33}$. De otra parte, todas las comarcas creadas cuentan, entre sus competencias propias, con las de asistencia y cooperación con los municipios y garantía de la prestación por éstos de sus servicios ${ }^{34}$, con competencias, por tanto, sustancialmente coincidentes con

28 En efecto, la generalidad de los Estatutos de Autonomía recogen la entidad comarcal aunque no siempre con el mismo carácter. Hay Comunidades Autónomas para las que la comarca constituye, otra cosa es que se haya procedido a su efectiva implantación, una entidad de carácter necesario en su territorio. Son los casos de Cataluña (artículo 83.2), Aragón (artículo 5), Murcia (artículo 3.2) y Principado de Asturias (artículo 6.1). Otras Comunidades Autónomas, por el contrario, se limitan a establecer su posible existencia dejando en manos de sus Parlamentos la decisión sobre su creación. Así ocurre en Cantabria (artículo 2.3), La Rioja (artículo 5.2), Castilla-La Mancha (artículo 29), Castilla y León (artículo 46), Extremadura (artículo 57), Valencia (artículo 65) o Andalucía (artículo 97.2). Existen, desde otro punto de vista, Comunidades Autónomas en las que la comarcalización, como sucede en Cataluña, ha de abarcar todo su territorio (artículo 83.2), esto es, no cabe la Comarca como respuesta a las necesidades propias de espacios concretos, carácter que es, justamente, el que asume en otras Comunidades como, por ejemplo, en Andalucía según resulta del artículo 97 de su Estatuto de Autonomía.

29 En sentido contrario a esa interpretación, A. J. FERREIRA FERNÁNDEZ, Régimen jurídico de la Comarca en el sistema autonómico español, pág. 280, 1991, Barcelona: Cedecs.

30 Así, el artículo 25.1.b) del Decreto Legislativo 4/2003, de la organización comarcal de Cataluña, dispone que corresponde a la entidad comarcal el ejercicio de las competencias que le «atribuyan las Leyes del Parlamento». Una atribución por leyes sectoriales que «tiene que hacerse teniendo en cuanta la tipología de las comarcas, sin perjuicio de la atribución directa de competencias a los ayuntamientos de los municipios que cumplan los requisitos mínimos de población, capacidad económica o capacidad de gestión, de acuerdo con los criterios objetivos que establezcan las mismas leyes sectoriales».

31 El artículo 4 de la Ley 1/1991, de 22 de abril, que crea y regula la Comarca del Bierzo, modificada por la Ley 17/2010, de 20 de diciembre, delimita, en efecto, esas materias. Entre otras, ordenación del territorio, urbanismo, protección civil, cultura, deporte, turismo, energía y minas o industria.

32 Artículos 9 y 16 y siguientes del Decreto Legislativo 1/2006, de 27 de diciembre, del Texto Refundido de la Ley de comarcalización de Aragón.

33 Sobre tal forma de atribución de competencias me remito a las consideraciones, entre otras, de J. LÓPEZ-MEDEL BASCONES y M. ZAFRA VÍCTOR (“Análisis del papel y funciones de los Gobiernos locales intermedios: propuestas de articulación”, Elementos para un debate sobre la reforma institucional de la planta local en el Estado autonómico, págs. 250-282, 2012, Madrid: Fundación Democracia y Gobierno local), o las de este último autor en "La intermunicipalidad, modelo de Estado. La provincia en el Estado autonómico" (COSCULLUELA MONTANER, L.; MEDINAALCOZ, L. (dirs.) y HERNANDO RYDINGS, M. (coord.): Crisis económica y reforma del régimen local, pág 127, 2012, Cizur Menor: Thomson Reuters).

34 Así el artículo 5.c) de la Ley de la Comarca del Bierzo, dispone la posible prestación por la entidad de los servicios «de competencia municipal cuando su realización o prestación resulte imposible o muy difícil para el municipio y razones de economía y eficacia así lo aconsejen»; el 8 atribuye al «Servicio de cooperación y asistencia municipales», a crear por «acuerdo del Pleno Comarcal y, en su caso, en colaboración con la Diputación Provincial de León», unas funciones de auxilio y cooperación con los municipios prácticamente coincidentes con las propias de las diputaciones de acuerdo con lo establecido en el artículo 36 de la LBRL; y el 9 prevé que la diputación pueda delegar en la comarca la gestión en su territorio del plan provincial de obras y servicios, así como «la asistencia y cooperación técnica, jurídica y económica a los municipios». 
las de las diputaciones ${ }^{35}$. Nada se opone, desde luego, a que dos o más instancias realicen unas mismas funciones, aunque es igualmente claro que el ejercicio por las comarcas de cometidos de esa naturaleza implica un debilitamiento de las diputaciones que han de compartir su función más característica con estas nuevas entidades. Ante esta situación, y aun reconociendo que la comarca «ofrece la ventaja de responder a la cercanía geográfica y la tradición compartida de los municipios que la integran ${ }^{36}$, son muchas las voces que, en los últimos años, han defendido la necesidad de «determinar a cuál de las dos» instancias, diputación o comarca, «debe corresponder la asistencia a los pequeños municipios» ${ }^{37}$, de deslindar «la propia razón de existir» de las distintas entidades que «integran la "planta local"»" aunque sin avanzar, por lo general, en propuestas concretas que permitan una mejor definición del cometido a cumplir por una y otra, más allá de esas genéricas apelaciones a la posible utilización de las comarcas «como instancias político-administrativas intermedias entre municipios y provincias que lleven a la reorganización y simplificación del mapa municipal, en particular en las áreas de dominio rural» ${ }^{39}$, o como «demarcación territorial idónea para la prestación de las competencias provinciales» ${ }^{40}$, para «el ejercicio de las funciones y la gestión de los servicios cuyo ámbito óptimo de desarrollo sea el supramunicipal e infraprovincial» ${ }^{41}$, lo que, como también se ha dicho, la convertiría en una comarca complementaria a la provincia, «sumatoria en pro de los intereses de los ciudadanos, especialmente de los que residen en los municipios más pequeños» ${ }^{42}$, aunque sin perder de vista que "las funciones de solidaridad y equilibrio intermunicipal» que la Constitución impone «no pueden ser satisfechas por las Comarcas, por el simple dato de que tales funciones sólo podrán darse entre los municipios de cada

Por su parte, el artículo 28.1 del Decreto Legislativo 4/2003, de 4 de noviembre, del Texto Refundido de la Ley de la Organización comarcal de Cataluña, establece que «corresponde a las comarcas prestar asistencia técnica, jurídica y económica a los municipios» y «cooperar económicamente en la realización de las obras, los servicios o las actividades de los municipios» y «en el establecimiento de nuevos servicios necesarios para el desarrollo del territorio». Igualmente, han de "garantizar, subsidiariamente, la prestación de los servicios municipales obligatorios en los municipios que, por razón de su población, no están obligados a prestarlos». Aclara además la norma en su apartado $2 .^{\circ}$ que «la comarca tiene que ejercer las funciones de asistencia y de cooperación que le corresponden teniendo en cuenta las necesidades de los diferentes municipios, tanto en lo que concierne al número de habitantes como a la situación geográfica o a su tipología en cuanto a la actividad económica predominante». El artículo 30 prevé que «sin perjuicio de las competencias que en este ámbito corresponden también a las diputaciones provinciales», en cada comarca exista, en principio, «un servicio de cooperación y de asistencia municipales encargado de asesorar a los municipios que lo soliciten en materia jurídico administrativa, económico financiera y de obras y servicios».

Finalmente, el artículo 12.1 del Decreto Legislativo 1/2006, de 27 de diciembre, del Texto Refundido de la Ley de comarcalización de Aragón, dispone que «sin perjuicio de las competencias que en este ámbito corresponden a las provincias, cada comarca podrá crear un servicio de cooperación y de asistencia dirigido a prestar asesoramiento a los municipios que lo soliciten en materia jurídico administrativa, económica y financiera y de obras y servicios».

35 Sorprende además el hecho de que en algunos de los territorios comarcalizados se hayan además constituido mancomunidades para la gestión de estos mismos servicios. Así, los Municipios que integran, de acuerdo con lo dispuesto en el artículo 1.2 de su Ley reguladora, la Comarca del Bierzo, pertenecen a distintas Mancomunidades encargadas de la gestión de numerosos servicios municipales. Concretamente a las Mancomunidades de «Municipios del Agua del Bierzo», del «Bierzo Alto», «Bierzo Central», «Bierzo Oeste» o «Bierzo Suroeste» entre cuyos fines figuran la prestación de los servicios de abastecimiento y depuración de aguas, recogida y tratamiento de residuos y prevención y extinción de incendios. La propia página web de la Comarca del Bierzo da además cuenta de la existencia de dos consorcios integrados por la entidad comarcal y diversos municipios, el consorcio «Ponfeblino» que tiene por objeto «la recuperación del tren minero entre Ponferrada y Villablino como recurso turístico» y el Consorcio «Los ancares leones», constituido con el fin de «contribuir a la conservación de los paisajes, los ecosistemas y de las especies» de este singular espacio.

36 M. SALVADOR CRESPO, "El papel de los gobiernos locales intermedios en la actualidad", op. cit., pág. 8.

37 L. COSCULLUELA MONTANER, "Problemática de la Provincia como entidad local", Crisis económica y reforma del régimen local, op. cit., pág. 124.

${ }_{38}$ F. VELASCO CABALLERO, "La planta local en España: criterios para la toma de decisiones", Anuario de Derecho Municipal 2010, pág. 31, 2011.

39 G. MORALES MATO y B. MÉNDEZ GARCÍA, "Despoblación rural, comarcas y áreas metropolitanas en España”, El futuro de la Administración local y el papel de los Gobiernos locales intermedios, op. cit., pág. 125.

40 Así por el Libro verde. Los gobiernos locales intermedios (op. cit., pág. 166-167) o por M. ARENILLA SÁEZ ("El pequeño municipio: núcleo democrático vs. prestación de servicios", Elementos para un debate sobre la reforma institucional de la planta local en el Estado autonómico, op. cit., pág. 213).

41 En tal sentido, M. ALMEIDA CERRADA ("La reforma de la planta local, estructura competencial, organización y articulación de la Administración local", J. J. DÍEZ SÁNCHEZ (coord.): La planta del Gobierno Local: actas del VIII Congreso de la Asociación Española de Profesores de Derecho Administrativo, Asociación española de Profesores de Derecho Administrativo-Fundación Democracia y Gobierno Local, Madrid, págs. 100-101, 2013) o L. COSCULLUELA MONTANER ("El debate sobre la abolición de la provincia y la reforma de las diputaciones", Anuario del Gobierno local 2011, pág. 64, 2011, Fundación Democracia y Gobierno local-Institut de Dret Public, y "Problemática de la Provincia como entidad local", op. cit., pág. 121).

42 M. BEATO ESPEJO, "Las diputaciones provinciales del territorio de la Comunidad Autónoma de Extremadura, a los diez años de vigencia de la Ley reguladora de las bases del régimen local”, La provincia en el Estado de las autonomías, págs. 260-261, 1996, Diputación de Barcelona-Marcial Pons. 
comarca si acaso, pero nunca entre todos los municipios de la Provincia» ${ }^{43}$. Desde luego, no cabe negar la posibilidad de que la comarca se convierta, en definitiva, en instancia intermedia entre municipios y provincias para el ejercicio de aquellas competencias, la prestación de esos servicios que encuentren en esa escala infraprovincial pero supramunicipal su nivel óptimo de prestación. Ahora bien, habría que reflexionar también sobre hasta qué punto está justificada, en términos de racionalidad de la estructura administrativa y gasto público, la existencia de dos entidades llamadas a realizar funciones coincidentes en ámbitos territoriales necesariamente reducidos y en los que ya concurren además otros niveles de gobierno. Quizás, y en términos jurídicos -distinta es, por supuesto, la valoración política que pueda efectuarse-, la comarca solo tenga cierto sentido, también podrían, desde luego, utilizarse a tal fin las diputaciones, al servicio de un proceso de descentralización de competencias autonómicas, si es que se concluye que este es necesario y las Comunidades Autónomas están realmente dispuestas a llevarlo a cabo. El carácter insustituible de la provincia y la atribución a la comarca, entre sus cometidos más importantes, de una función coincidente con aquella en la que el Derecho básico estatal ha situado el núcleo esencial de su autonomía constitucionalmente garantizada, no puede más que conducir a la actual situación de solapamiento entre una Administración y otra y, en última instancia, a la indebida articulación del nivel supramunicipal de gobierno. Cabe pues seguir reivindicando ese «gran esfuerzo» al que se refería T. FONT en 1992 «de definición política y de determinación funcional» de la comarca «dentro del panorama de los entes locales intermedios» ${ }^{44}$.

\subsection{Las áreas metropolitanas}

Una situación parecida a la descrita es la que ofrece el análisis de las áreas metropolitanas, entidad local, en los términos en los que la define el artículo 43 de la LBRL, integrada «por los Municipios de grandes aglomeraciones urbanas entre cuyos núcleos de población existan vinculaciones económicas y sociales que hagan necesaria la planificación conjunta y la coordinación de determinados servicios y obras». Aunque el hecho metropolitano, las grandes concentraciones urbanas en las que de facto los términos municipales han desaparecido, es una realidad en nuestro país, las áreas metropolitanas cómo forma de gobierno y administración de estos espacios prevista en la LBRL y regulada por el ordenamiento autonómico, han tenido, sin embargo, un desarrollo muy escaso, pues tan solo se han constituido entidades de esta naturaleza para los espacios metropolitanos de Valencia, Barcelona y Vigo. Las Comunidades Autónomas, son ellas las que han de crearlas, no se han mostrado proclives a la instauración de este nivel de gobierno del territorio, pues, como se ha dicho, ven en estas entidades «a un competidor peligroso, más aún si son gobernadas por una fuerza política adversaria» ${ }^{45}$. Es por ello que, incluso, se ha llegado a expresar «la conveniencia de una intervención estatal de simple puesta en marcha de un proceso de institucionalización de las áreas metropolitanas en todo el territorio» ${ }^{46}$, aunque no faltan, desde posiciones distintas, quienes advierten sobre la innecesariedad de esta entidad toda vez que sus funciones «pueden alcanzarse por medios menos complejos como los consorcios» ${ }^{47}$.

El análisis de las áreas existentes arroja el siguiente resultado. La Comunidad de Valencia, tras no pocos vaivenes y cambios profundos en el modelo inicialmente adoptado ${ }^{48}$, se decanta en Ley $2 / 2001$, de 11

43 T. DE LA CUADRA-SALCEDO, "El debate sobre las diputaciones en un escenario de reforma constitucional del Título VIII", op. cit., págs. 13 y 19.

44 "Aproximación a la estructura de la Administración local en España", Informe sobre Gobierno Local, pág. 29, 1992, Madrid: Ministerio para las Administraciones Públicas.

45 T. FONT, "Uniformidad y diferenciación en las instituciones autonómicas y locales en España: Aquiles y la tortuga”, F. LÓPEZ MENUDO (dir.), Derechos y Garantías del ciudadano. Estudios en homenaje al Profesor Alfonso Pérez Moreno, pág. 1.234, 2011, Madrid: lustel.

46 T. FONT, "Los retos actuales del Gobierno local: Repolitización, diversificación, interiorización", (Memorial para la reforma del Estado: estudios en homenaje al Profesor Santiago Muñoz Machado, vol. 2, op. cit., pág. 1.937). En la misma línea, F. CASTILLO BLANCO ("La reforma de los gobiernos locales en España: ¿Una oportunidad perdida para lograr una planta local competitiva y sostenible?", Memorial para la reforma del Estado: estudios en homenaje al Profesor Santiago Muñoz Machado, vol. 2, op. cit., pág. 1.972-1.973).

47 M. ZAFRA VÍCTOR, "La provincia: lo importante no es el nombre, lo importante es la función. Intermunicipalidad en el Estado autonómico", op. cit., pág. 68.

48 En efecto, la Ley 12/1986, de 31 de diciembre, crea el Área Metropolitana de «L'Horta», como una Administración territorial delimitando una serie de materias sobre las que la entidad habría de ejercer competencias en los términos que dispusiera el legislador sectorial o los municipios que la integran. Las Leyes posteriores apenas otorgaron competencias al área de «L'Horta». Ante esta situación, la Ley 4/1995, de 16 de marzo, reforma la Ley originaria para, según expresa su Preámbulo, «aclarar el ámbito propio de actuación de la Entidad evitando las disfuncionalidades constatadas y dotando al ente de mayor efectividad en su gestión», aclaración que se traduce en la conversión del área en un ente para la prestación asociada de servicios municipales, carácter que mantendrá hasta que 
de mayo, opción que mantiene la Ley 8/2010, de 23 de junio, de Régimen Local de la Comunidad Autónoma, por la gestión sectorializada de los intereses de este espacio, al permitir la constitución de concretas áreas metropolitanas cuando "así lo requiera la prestación de un determinado servicio público». La propia Ley creaba la «Entidad Metropolitana de Servicios Hidráulicos», con competencias sobre el «servicio del agua en alta, la producción y suministro hasta el punto de distribución municipal», y la «Entidad Metropolitana para el Tratamiento de Residuos», con el objeto de prestar «los servicios de valoración y eliminación de residuos urbanos, de acuerdo con los objetivos marcados por la Generalitat, a través de la normativa sectorial y de conformidad con los instrumentos de planificación en ella previstos» ${ }^{49}$. Cataluña por su parte, corrigiendo igualmente el modelo de administración del espacio metropolitano de Barcelona diseñado en $1987^{50}$, crea por la Ley 31/2010, de 3 de agosto, el Área metropolitana de Barcelona, que su artículo primero define como «un ente local supramunicipal de carácter territorial». Una opción por la que se decanta también la Ley gallega 4/2012, de 12 de abril, para el Área metropolitana de Vigo ${ }^{51}$. De forma coherente con la naturaleza territorial del ente que crean, estas Leyes les atribuyen diferentes competencias en materias, entre otras, de urbanismo, transporte, movilidad, aguas, residuos, medio ambiente, infraestructuras de interés metropolitano, turismo, promoción cultural, movilidad y transporte o desarrollo económico y social ${ }^{52}$. Unas competencias inicialmente autonómicas y de las que la propia Comunidad dispone en beneficio de la entidad metropolitana en un proceso de descentralización de competencias que da sentido a este nivel intermedio de gobierno entre la propia Comunidad Autónoma y los municipios del área. Ahora bien, también las áreas metropolitanas existentes tienen atribuida la prestación de servicios que la norma que las crea considera que deben ser gestionados a escala supramunicipal ${ }^{53}$, así como, es el caso de la entidad gallega, funciones de asistencia y cooperación con los municipios ${ }^{54}$, en detrimento, de nuevo, de las diputaciones que ven como, también de la mano de estas entidades, su función de apoyo a los municipios puede verse mermada, cuando no abiertamente excluida. De hecho, diferentes autores han venido en los últimos años advirtiendo sobre la difícil convivencia entre áreas metropolitanas y diputaciones, apuntándose, así lo hizo M. BASSOLS, que por «el legislador básico estatal no debería abandonarse la posibilidad de que las Diputaciones provinciales pudieran participar en alguna medida en la gestión metropolitana o incluso asumir un protagonismo de gobierno, con el consentimiento de los Municipios del área» "55; o, como es el caso de T. FONT, a una posible "refundación» de la provincia por su «refundición» con otros niveles supramunicipales" o, de no existir coincidencia entre sus términos territoriales, «soluciones que permitan adecuar la organización de la provincia que contenga un área metropolitana en su interior a esta realidad, retirándose en su función de ente supramunicipal en ese territorio» ${ }^{56}$. Por su parte, la Fundación Democracia y Gobierno Local ha planteado «si no cabría insertar de algún modo más intenso a la Diputación Provincial en la propia organización institucional del área» ${ }^{57}$, y se ha propuesto también la posibilidad de que las áreas metropolitanas, «a través de las correspondientes téc-

la Ley 8/1999, de 3 de diciembre, procede a su supresión en el intento, según declara de nuevo el Preámbulo, «de huir de la creación de órganos dotados de rígidas y pobladas estructuras permanentes, así como en la voluntad de buscar fórmulas de gestión más ágiles y eficaces».

49 Interesa señalar también que los Municipios que forman parte de las entidades metropolitanas se encuentran mancomunados para la gestión de fines muy diversos. De hecho, en el espacio metropolitano de Valencia existen dos Mancomunidades de fuerte implantación en la zona, la de «L'Horta Nord» y la de «L'Horta Sud», con cometidos muy importantes en ámbitos diversos.

50 La Ley 7/1987, de 4 de abril, creó para el área de Barcelona la «Entidad Metropolitana de Servicios Hidráulicos y Tratamiento de Residuos» y la «Entidad Metropolitana de Transportes». La primera, artículo 15.a), tenía por objeto «la prestación del servicio de transporte público de viajeros en el área»; la segunda, artículo 17, «la coordinación de los servicios en el ámbito de su competencia y la realización, establecimiento y prestación de los servicios relacionados con la captación, tratamiento y distribución de agua potable y con el tratamiento y eliminación de las residuales».

51 Su artículo 1.2 la define, en efecto, como «entidad local supramunicipal, de carácter territorial».

52 Los artículos 14 de la Ley catalana y 15 de la gallega delimitan, en términos similares, esos ámbitos materiales.

53 Es el caso del servicio de abastecimiento domiciliario de agua potable según disponen las Leyes del área metropolitana de Vigo (art. 23) y de Barcelona (art. 14.C).

54 Así el artículo 30 de la Ley del Área metropolitana de Vigo, determina que «podrá ejercer funciones de asistencia y cooperación con los municipios integrados en ella, especialmente con los de menor capacidad económica y de gestión, para colaborar en el cumplimiento de sus obligaciones urbanísticas. En este sentido, se determinará en la comisión mixta paritaria la transferencia de competencias en esta materia por parte de la Diputación Provincial de Pontevedra a favor del área metropolitana, así como los recursos económicos, humanos y materiales para su ejercicio».

55 "Las diputaciones provinciales a los diez años de la Ley Reguladora de las Bases del Régimen Local: Experiencias y perspectivas", (La provincia en el Estado de las autonomías, op. cit., pág. 465). En esta misma línea de integración entre diputaciones y áreas metropolitanas pueden verse las consideraciones de A. SÁNCHEZ BLANCO, Organización intermunicipal, págs. 94-99, 2006, Madrid: Iustel.

56 "Los retos actuales del Gobierno local: Repolitización, diversificación, interiorización", op. cit., págs. 1.937-1.938.

57 Libro verde. Los Gobiernos locales intermedios en España, op. cit., págs. 75-76 y 169-173. 
nicas de asignación o delegación competencial», lleven «a cabo, prácticamente, las mismas funciones que las diputaciones, las cuales, por consiguiente, concentrarían su actividad en el resto de los municipios, sobre todo en los de carácter rural» ${ }^{58}$, llegándose, incluso, a decir que el área metropolitana "vendría a ser para sus integrantes una "mini provincia" en todos sus aspectos» que debe "coordinarse con la propia provincia en las grandes cuestiones estratégicas: residuos, aguas, movilidad, infraestructura.... ${ }^{59}$. Desde luego, son propuestas a considerar aunque habrá que examinar detenidamente, sobre todo allí donde la fórmula que se apunta parece implicar la pérdida por las diputaciones de todas sus competencias en estas áreas, en qué medida soluciones de este tipo pudieran atentar contra la propia posición constitucional de la provincia en los términos en los que ha sido interpretada por la jurisprudencia constitucional.

\subsection{Las mancomunidades de municipios}

Las mancomunidades de municipios cierran el elenco de entidades que conforman, de acuerdo con lo dispuesto en la LBRL y el Derecho dictado en su desarrollo, el nivel intermedio de gobierno local en su actual configuración, aunque es probable que, a día de hoy, sea necesario añadir a los consorcios que el propio artículo 26.2 de esta Ley, tras su reforma de 2013, considera una de las fórmulas posibles de gestión, junto con la mancomunidad, para la prestación de los servicios de los municipios de menos de 20.000 habitantes. Algunas disposiciones autonómicas les confieren funciones similares a las de las mancomunidades ${ }^{60}$. Y no faltan, incluso, voces que proponen la unificación de una y otra entidad "en una única figura jurídica" 61.

Las mancomunidades, entidades, a diferencia de las anteriores, surgidas del derecho de asociación de los municipios para, según dispone el artículo 44.1 de la LBRL, «la ejecución en común de obras y servicios determinados de su competencia», han experimentado un extraordinario desarrollo bajo la vigencia de esta disposición que ha contado con el impulso decidido de las Comunidades autónomas cuyo ordenamiento las han fomentado claramente ${ }^{62}$, apostando además por las denominadas mancomunidades «integrales», de «interés general», «comunitario», «comarcal» o «de ámbito comarcal» ${ }^{63}$. En definitiva, por ese modelo de mancomunidad que el entonces Ministerio para las Administraciones Públicas calificaba en 1994 como «mancomunidad evolucionada», en referencia a aquella «en la que se enuncian una pluralidad de fines específicos que irán abordándose sucesivamente para su puesta en funcionamiento y que, más bien, por ello, constituyen un programa de futuras realizaciones y en el que se pone de manifiesto una voluntad política de declinar competencias municipales en favor de ir configurando a través de la asociación voluntaria, un

58 J. L. CARRO FERNÁNDEZ-VALMAYOR, "La Administración local en el espacio autonómico" (Congreso Internacional Municipia Siglo XXI. Ciudadanía y Gobierno Local, págs. 12-13, 2004, Zaragoza). En un estudio posterior el autor parece, sin embargo, apuntarse a las tesis de T. FONT al señalar como «sería, quizás, oportuno plantearse si estas (las áreas metropolitanas) no habrían de llevar a cabo, en el territorio metropolitano, las mismas funciones que las Diputaciones, sustituyendo, por tanto, a las mismas. En este caso las Diputaciones podrían concentrar su actividad en el resto de los Municipios rurales o pequeños Municipios, tal como quiere, por lo demás, nuestra legislación local», solución que, a su juicio, no afectaría, «al contenido esencial de la garantía institucional de la Provincia, la cual no sufriría, en ningún caso, un vaciamiento competencial como Entidad local necesaria incompatible con dicha garantía. Por lo demás, con la finalidad de una estructuración más eficaz de la organización autonómica interna, la delimitación de ámbitos de actuación de las Áreas Metropolitanas y las Diputaciones Provinciales en el territorio metropolitano podría encontrar en la eventual creación de una Comisión de Coordinación o de Cooperación el instrumento más conveniente para su mejor realización» (“Articulación organizativa y Estado compuesto", op. cit., pág. 15).

59 F. FERNÁNDEZ-FIGUEROA GUERRERO, "De la «cooperación» en el plan provincial de cooperación a las obras y servicios municipales a la "concertación» en otros instrumentos de planificación", El futuro de la Administración local y el papel de los Gobiernos locales intermedios, op. cit., pág. 460.

60 Es el caso de Andalucía cuya Ley 5/2010, de 11 de junio, de Autonomía local, considera tanto a mancomunidades como a consorcios «entidades de cooperación territorial», definiendo sus objetos en términos muy similares. En el primer caso, artículo 63, «la planificación, establecimiento, gestión o ejecución en común de obras y servicios determinados de competencia propia»; en el segundo, artículo 78, «crear y gestionar servicios y actividades de interés común».

61 Así F. FERNÁNDEZ-FIGUEROA GUERRERO que añade que el régimen jurídico de la nueva figura vendría «determinado por la refundición de las regulaciones actuales de ambos» ("De la «cooperación» en el plan provincial de cooperación a las obras y servicios municipales a la «concertación» en otros instrumentos de planificación", op. cit., pág. 476).

62 Como puede comprobarse, entre otros, en los artículos 32.3 de la Ley 1/1998, de 4 de junio, de Régimen Local de Castilla y León, en la redacción dada por la Ley $7 / 2013$, de 27 de septiembre de Ordenación, Servicios y Gobierno del Territorio de la Comunidad; 83.4 de la Ley 7/1999, de 9 de abril, de Administración local de Aragón; 64 de la Ley 17/2010, de 22 de diciembre, de Mancomunidades y entidades locales de Extremadura; o 50 de la Ley 21/2018, de 23 de junio, de Mancomunidades de la Comunidad de Valencia.

63 Así, respectivamente, Leyes 17/2010, de 22 de diciembre, de Mancomunidades y entidades locales de Extremadura (artículo 19); 1/1998, de 4 de junio, de Régimen local de Castilla y León (artículo 32); 1/2003, de 3 de marzo, de Administración local de La Rioja (artículo 60); 7/1999, de 9 de abril de Administración Local de Aragón (artículo 86); y Ley 21/2018, de 23 de junio, de Mancomunidades de la Comunidad de Valencia artículos 2 y 13). 
nuevo ente local supramunicipal que asuma la prestación de los servicios municipales (no solo los mínimos u obligatorios), mientras que se reservan los Municipios mancomunados las competencias más vinculadas territorialmente, cual la administración del patrimonio, las funciones representativas, etc.»1 ${ }^{64}$. Parece así evidente que la mancomunidad se ha convertido en una entidad dotada de un extraordinario protagonismo en ese mismo nivel de gestión de los intereses públicos, el supramunicipal, que la LBRL asigna, en principio, a las diputaciones. De hecho, no son pocos los autores que vienen reivindicando, en el sentido apuntado por la propia FEMP 65 , la necesidad de «establecer con claridad el marco de actuación que corresponde a las diputaciones provinciales y a las mancomunidades de municipios» ${ }^{66}$ y de "reforzar» el papel de las primeras en detrimento precisamente del de «aquellas mancomunidades que no asumen la ejecución de obras 0 servicios determinados sino otras actividades genéricas e indeterminadas que bien podrían ser gestionadas por las diputaciones provinciales» ${ }^{67}$. De igual forma, se ha postulado que las mancomunidades se creen solo para prestar «el conjunto de competencias puntuales, más afines a una modalidad de prestación de servicios que a una entidad local de fines universales» ${ }^{68}$, con «una disponibilidad limitada centrada, en lo esencial, en la prestación de servicios no obligatorios» ${ }^{69}$; e, incluso, se ha llegado a proponer «su posible supresión», de la mano de «la revisión de las competencias obligatorias de los pequeños municipios y su posible traspaso a las diputaciones ${ }^{70}$. El movimiento crítico existente en torno a esta entidad alcanza igualmente, y sin desconocer las ventajas que aportan, a las carencias derivadas de su propia «voluntariedad» ${ }^{71}$, «las duplicidades organizativas» que generan ${ }^{72}$, sus "graves inconvenientes desde el punto de vista del principio democrático» o la «devaluación que implican del principio constitucional de "centralidad municipal"» ${ }^{73}$. Valoraciones doctrinales al margen, no pueden dejar de señalarse los intentos de la reforma legal de 2013 , fallidos en este como en tantos otros extremos, de reconducir la figura al estricto cumplimiento de los fines propios de la entidad de acuerdo con lo establecido en el artículo 44 de la LBRL. En efecto, tras el abandono de las posiciones iniciales del Gobierno partidario, según quedaría plasmado en las primeras versiones del Anteproyecto de Ley, de la disolución de todas las mancomunidades "cuya sostenibilidad financiera no esté asegurada» ${ }^{74}$, la disposición transitoria undécima de la Ley, introducida por el Congreso de los Diputados como consecuencia de la aceptación de una enmienda presentada por el Grupo parlamentario popular, sin más justificación que la de «concretar el objeto de las mismas» ${ }^{75}$, impone a las mancomunidades «un deber de adaptar sus

64 J. D’ ANJOU GONZÁLEZ, Las Mancomunidades intermunicipales en el Régimen local español. Antecedentes, situación actual y catálogo de las mismas (1994), págs. 19-20, 1994, Madrid: Ministerio para las Administraciones Públicas.

65 "Propuestas de la Comisión de Diputaciones Provinciales, Cabildos y Consejos Insulares de la Federación Española de Municipios y provincias: Fortalecimiento institucional y modernización de las diputaciones, cabildos y consejos insulares y demás entidades locales intermedias" de 10 de abril de 2012.

66 M. R. ZAMORA ROSELLÓ, "La reestructuración de la planta del gobierno local y las mancomunidades de municipios", La planta del Gobierno local, op. cit., págs. 143-144.

67 E. CARBONELL PORRAS, “¿Existe un criterio sobre las diputaciones provinciales? Algunas reflexiones sobre la provincia en Andalucía”, Crisis económica y reforma del régimen local op. cit., pág. 190.

68 M. ZAFRA VÍCTOR, "El debate sobre la supresión o reforma de las diputaciones provinciales en España", Cuadernos de Derecho Local (QDL), núm. 27, 2011, pág. 96.

69 F. CASTILLO BLANCO: "La reforma de los gobiernos locales en España: ¿Una oportunidad perdida para lograr una planta local competitiva y sostenible?”, op. cit., pág. 1.973.

70 M. ARENILLA SÁEZ, "El pequeño municipio: núcleo democrático vs. prestación de servicios", op. cit., pág. 193.

71 J. LÓPEZ-MEDEL BASCONES y M. ZAFRA VÍCTOR (“Análisis del papel y funciones de los Gobiernos locales intermedios: propuestas de articulación”, op. cit., págs. 260-261) o M. ZAFRA (“La intermunicipalidad, modelo de Estado. La provincia en el Estado autonómico", op. cit., págs. 125 y "La provincia: lo importante no es el nombre, lo importante es la función. Intermunicipalidad en el Estado autonómico", op. cit., pág. 68).

72 J. J. DÍEZ SÁNCHEZ, "Estrategias para ganar tamaño en la gestión administrativa tras la reforma local de 2013", A. BOIX PALOP y A. M. DE LA ENCARNACIÓN (coords.), Los retos del Gobierno local tras la reforma de 2013, pág. 157, 2015, Cizur Menor: Thomson Reuters-Aranzadi.

73 F. VELASCO CABALLERO, "Competencias para la reforma de la planta municipal", Cuadernos de Derecho Local (QDL), núm. 29, 2012, págs. 62-63.

74 Coherente con esta posición de partida, se las obligaba a presentar sus cuentas, en los tres meses siguientes a la entrada en vigor de la Ley, ante "los organismos correspondientes del Estado y de la Comunidad Autónoma» con riesgo, en caso contrario, de disolución de la entidad. Además, y en el plazo de un año, los servicios de la mancomunidad serían valorados de acuerdo con el coste estándar que entonces preveía el artículo 26.2, asumiéndolos la diputación si de dicha evaluación resultaba «la inadecuación de la prestación». El propio Gobierno sin embargo, movido probablemente por la oposición que la decisión suscita, así como por los reparos expresados por el Dictamen del Consejo de Estado 567/2013, retira dichas previsiones, de tal forma que el Proyecto de Ley mantiene la regulación de las mancomunidades prevista en la LBRL sin alteración alguna.

75 Enmienda número 42, Boletín Oficial de las Cortes Generales. Congreso de los Diputados, X Legislatura, Serie A, núm. 58.2, de 30 de octubre de 2013 
estatutos a lo previsto en el artículo 44» de la LBRL, en el plazo de seis meses, para «no incurrir en causa de disolución». Aunque la disposición, declarada conforme a la Constitución por la Sentencia del Tribunal Constitucional 41/2016, de 3 de marzo, no es suficientemente clara, parecía evidente, y así lo confirmó el Ministerio de Hacienda y Administraciones Públicas en su «Nota explicativa» sobre la aplicación de la Ley de 4 de marzo de 2014, que afectaba al «objeto y competencias» de la entidad, lo que es lógico toda vez que la Ley ha modificado las competencias de los municipios. Ahora bien, puede ser también que ese obligado proceso de adaptación de las competencias de las mancomunidades a lo dispuesto en el artículo 44 de la LBRL, respondiera, igualmente, a la preocupación del legislador básico estatal de reconducir a la entidad al ámbito en el que este precepto la sitúa, la ejecución de obras o prestación de servicios de competencia municipal, ante esa proliferación de mancomunidades vinculadas a la satisfacción de una pluralidad de fines muy diversos a medio y largo plazo ${ }^{76}$. La interpretación sin embargo, no es momento de entrar en su análisis, que finalmente se va a imponer sobre el alcance de la modificación de las competencias municipales, favorable, en último término, al mantenimiento del status quo anterior a la reforma, explica la escasa significación que este proceso ha tenido. Tampoco puede pasar desapercibido que la apuesta de las Comunidades Autónomas por esas mancomunidades de objeto amplio sigue plenamente vigente, como lo confirma la definición que de las mismas ofrece la aún reciente Ley 21/2018, de 16 de octubre, de Mancomunidades de la Comunidad de Valencia, como «entidades locales territoriales» constituidas "para gestionar o ejecutar planes, realizar proyectos y obras o prestar servicios de su competencia a los ciudadanos, acercándoles la administración y potenciando un desarrollo social y económico sostenible, equilibrado e igualitario de estos municipios y sus respectivos territorios».

\section{Algunas ideas conclusivas}

El análisis efectuado nos deja las siguientes conclusiones de interés.

1. La implantación, con grados de desarrollo diferentes en las distintas Comunidades Autónomas, de un nivel de gobierno supramunicipal paralelo al provincial con el que este necesariamente ha de convivir. La norma fundamental, en una decisión de resultados, según parece haber demostrado el tiempo transcurrido, más que dudosos, abrió la puerta a una posible organización supramunicipal distinta a la provincial, pero sin establecer criterio alguno de diferenciación entre ese escalón supramunicipal necesario y ese otro disponible por las Comunidades Autónomas. De esta forma, resulta muy difícil ahormar uno y otro, como ha evidenciado el ordenamiento dictado en su aplicación y una realidad contraria, cuando menos, a la necesaria racionalidad que debe presidir cualquier sistema de Administraciones Públicas.

2. Una visión de conjunto de la organización supramunicipal, a día de hoy, permite, en efecto, comprobar como son muchos los extremos que la definen precisados de reflexión y mejora. En síntesis, y recapitulando cuanto se ha dicho, nos encontramos con la consolidación de una provincia vertebrada en torno la asistencia que la diputación presta a los municipios de menor capacidad económica y de gestión, con la consecuencia -resultado que no estaba, desde luego, predeterminado en la Constitución- de que la diputación carece de todo protagonismo respecto de un buen número de municipios a los que igualmente integra. Y con la consecuencia, también, de que no se ha producido un desarrollo, lo que tampoco parece prohibido por la norma fundamental, de competencias sustantivas o materiales en su favor, lo que, sin duda, hubiera contribuido a reforzar este nivel de gobierno. De otra parte, y si la atención se centra en la organización supramunicipal no necesaria, pueden destacarse, aunque estemos ante un nivel de gobierno que puede ser muy distinto en los diferentes territorios, dos rasgos comunes. A saber: a) La existencia de una confusión clara sobre la función con la que han de cumplir las diferentes entidades previstas por la LBRL y desarrolladas por el ordenamiento autonómico, pues todas ellas han terminado por servir a unos mismos fines. La cooperación con los municipios en la prestación de sus servicios o la gestión de los mismos a nivel supramunicipal, puede igual constituir el cometido propio de una comarca que el de un área metropolita, el de una mancomunidad e, incluso, el de un consorcio; y b) La consolidación de un nivel supramunicipal que,

76 Numerosas decisiones adoptadas tanto a nivel estatal como autonómico confirman esta interpretación. Por ejemplo, y en el ámbito estatal, la Circular de la Dirección General de los Servicios Jurídicos y Coordinación territorial de la Federación española de Municipios y Provincias sobre "Las mancomunidades tras la entrada en vigor de la Ley 27/2013"; en el autonómico, entre otras, el Decreto Ley de la Junta de Extremadura 3/2014, de 10 de junio, que modifica la Ley 17/2010, de 22 de diciembre, de Mancomunidades y entidades locales menores. 
al haber hecho precisamente de esas competencias, los ejes esenciales de su labor, ha venido a situarse, no ya desde el punto de vista territorial, sino también material, en el mismo espacio que ocupa la provincia, con la que, por consiguiente, difícilmente convive, hasta el punto de que haya podido afirmarse que aquí radica «uno de los puntos necesariamente focales en el contexto de revisión de las estructuras locales» ${ }^{77}$. La revisión parece, en efecto, obligada una vez consolidado el Estado autonómico surgido de la Constitución de 1978 y con la experiencia aportada por este ya amplio periodo histórico.

\section{UNA REFORMA NECESARIA, QUÉ REFORMA ES POSIBLE}

Pocos dudan sobre la necesidad de un nivel intermedio de gobierno local ante la fragmentación del mapa municipal, pero, también, ante la realidad representada por las grandes aglomeraciones urbanas en las que el término municipal no siempre constituye el nivel territorial óptimo para el ejercicio de determinadas competencias. No parece discutible, por tanto, que este nivel de gobierno ha de dar respuesta satisfactoria a las necesidades, muy distintas entre sí, que presentan los diferentes territorios, como tampoco parece cuestionable el hecho de que en su actual configuración no lo hace, de ahí la necesidad de su modificación. Ahora bien, el consenso existente sobre la oportunidad de la reforma se pierde cuando el análisis se sitúa en su posible contenido, ámbito además en el que debe introducirse el factor relativo a quién puede efectuarla, toda vez que muchas de las propuestas que se han formulado a nivel doctrinal, o incluso político, en los últimos años, exigirían de una reforma constitucional. Diferenciare, por ello, en estas reflexiones finales entre aquellos posibles cambios en la organización supramunicipal resultado de una eventual modificación de la Constitución de 1978 y aquellos otros que pudieran venir de la mano del legislador ordinario, ya sea estatal o autonómico.

$\mathrm{Si}$, como hemos afirmado, muchas de las disfunciones que hoy presenta el escalón supramunicipal tienen su origen en la decisión constitucional favorable a la creación por las Comunidades Autónomas de circunscripciones territoriales propias que necesariamente han de sumarse a la provincia a la que, como dejó pronto establecido el Tribunal Constitucional, no pueden sustituir, parece evidente que la vía más adecuada para la mejor articulación de este nivel de gobierno sería la de una reforma constitucional que clarifique el modelo por el que se apuesta. Así, por uno caracterizado por una uniformidad absoluta sobre la base de la provincia sin la compañía de otros entes de naturaleza similar -opción, desde luego, poco acorde con la realidad política y jurídica en la que vivimos-; en el ángulo opuesto, por el definido por una diversidad resultado de las decisiones propias de las distintas Comunidades Autónomas y que pasaría, en el sentido defendido por un sector importante de la doctrina, por la eliminación de la provincia, al menos como ente indisponible ${ }^{78}$. Finalmente, por el que, como hoy ocurre, combine la instancia provincial con otro nivel supramunicipal paralelo a ella, en cuyo caso, lo que no sucede actualmente, tendrían que delimitarse con claridad las funciones propias de una y otro. Desde luego, se trata de un debate fundamental en el que no puede ocultarse la importancia, junto al razonamiento jurídico, de las distintas opciones políticas. Ahora bien, en un plano estrictamente jurídico, y puesto que no parece que hoy concurran las condiciones adecuadas para una reforma constitucional que permitiera, en su caso, disponer de las provincias y tampoco se atisba, en el sentido que apuntara L. COSCULLUELA, «una mutación constitucional, por cambio de la interpretación de los preceptos citados (artículos 137 y 141) por parte del Tribunal Constitucional», que pudiera abrir otras posibilidades de reestructuración de este nivel de gobierno ${ }^{79}$, lo más razonable, y también lo más útil, es partir del régimen constitucional vigente y analizar, por consiguiente, qué es lo que pudiera hacerse por parte del legislador ordinario en orden a una mejor articulación de la organización supramunicipal.

Ante todo, cabe plantear qué reformas o modificaciones podría realizar legislador básico estatal, siendo, desde luego, consciente de las dificultades del reparto de competencias en esta materia y de las dudas

77 A. EMBID IRUJO, "Reforma de la planta municipal y prestación de servicios locales", Cuadernos de Derecho Local (QDL), núm. 29, 2012, pág. 102

78 Así, y entre otros, M. SÁNCHEZ MORÓN (Derecho Administrativo, Parte general, pág. 386, Madrid: Tecnos, $15^{\circ}$. ed.), P. ESCRIBANO COLLADO ("Provincias y Diputaciones: una polémica sin proyecto institucional", op. cit., pág. 2.015) o A. BAYONA I ROCAMORA ("El orden constitucional actual: limitaciones, condicionantes y posibilidades de reforma de las diputaciones provinciales", EI futuro de la Administración local y el papel de los Gobiernos locales intermedios, op. cit., pág. 52).

El propio Consejo de Estado en su informe 1/2005, de 16 de febrero de 2006, sobre la reforma constitucional apuntó en esta línea.

79 "Problemática de la Provincia como entidad local" (op. cit., pág. 122) y "El debate sobre la abolición de la provincia y la reforma de las diputaciones" (op. cit., pág. 67). 
que, por consiguiente, pueden surgir ante una eventual modificación de la LBRL. De hecho, tanto el texto originario de la Ley de 1985, como las sucesivas reformas de las que ha sido objeto, han precisado, como sabemos, del pronunciamiento del Tribunal Constitucional.

Es probable, en primer término, que una mejor articulación del nivel supramunicipal de gobierno aconseje una reforma del régimen de las diputaciones. Aun cuando se ha afirmado que «no parece que sea mucho el margen de disponibilidad que tiene el legislador» ${ }^{80}$, cabe pensar en la posibilidad y oportunidad de esa modificación con, al menos, dos objetivos. De una parte, la definición de su papel en relación con los municipios que no precisan de esa labor de auxilio para la prestación de sus servicios que define actualmente el cometido de la entidad. Aunque se admita que la labor de las diputaciones deba centrarse «muy especialmente, en lo que antaño era y acaso debe ser su función esencial: la asistencia, no sólo económica, sino también técnica-organizativa, a los municipios más pequeños» ${ }^{81}$, habrá que determinar qué es lo que les corresponde hacer respecto del resto de los municipios a los que igualmente integra. No parece lógico sencillamente que las funciones de las diputaciones sobre muchos municipios se ignoren, si es que existen. De otra parte, habría que replantear el sentido y alcance de sus competencias. En efecto, sin poner en cuestión que su núcleo básico sea el constituido por esas funciones de auxilio al municipio, habría, por un lado, que avanzar normativamente en su mejor concreción y forma de ejercicio respecto de esas entidades sobre las que ya las desarrolla ${ }^{82}$, así como dotarla de contenido en su posible proyección sobre esos otros municipios en los que la necesidad de una actuación de asistencia y cooperación no deriva de su insuficiencia, sino de factores de otra índole, como un mejor y más eficiente ejercicio de algunas de sus competencias en zonas altamente pobladas en las que los términos municipales han quedado de facto superados. Ahora bien, es importante valorar también, en segundo lugar, la conveniencia, en el sentido defendido, es verdad que con excepciones significativas $^{83}$, por un sector importante de la doctrina y por instituciones diversas ${ }^{84}$, de la atribución a las diputaciones de competencias sustantivas o materiales que la Constitución no excluye y la LBRL permite, aunque sus previsiones en este sentido no hayan contado nunca con un desarrollo suficiente, imputable, en buena medida, al Derecho autonómico. Tampoco puede pasar desapercibido que otras entidades supramunicipales cuentan con competencias de esta naturaleza ${ }^{85}$. En síntesis, es preciso determinar si, como sostiene G. FERNÁNDEZ FARRERES, la consideración de la provincia como agrupación de municipios determina

80 G. FERNÁNDEZ FARRERES, "Qué hacer con las diputaciones provinciales (Presupuestos y límites constitucionales para su reforma)", op. cit., pág. 97

81 J. LÓPEZ-MEDEL BASCONES y M. ZAFRA VÍCTOR, "Análisis del papel y funciones de los Gobiernos locales intermedios: propuestas de articulación”, op. cit., pág. 270.

82 En tal sentido, J. M. CARBONERO GALLARDO (“EI nuevo papel de las Diputaciones provinciales”, J. A. CARRILLO DONAIRE y P. NAVARRO RODRÍGUEZ (coord.), La reforma del Régimen Jurídico de la Administración Local. El nuevo marco regulatorio a la luz de la Ley de Racionalización y Sostenibilidad de la Administración Local, pág. 260, 2014, Madrid: La Ley), G. FERNÁNDEZ FARRERES ["Qué hacer con las diputaciones provinciales (Presupuestos y límites constitucionales para su reforma)", op. cit., págs. 100-101], F. FERNÁNDEZ-FIGUEROA GUERRERO (“De la «cooperación» en el plan provincial de cooperación a las obras y servicios municipales a la «concertación» en otros instrumentos de planificación”, op. cit., págs. 461-476), o L. PAREJO ALFONSO (“Algunas reflexiones sobre posibles líneas maestras de arreglo de la provincia y la diputación peninsulares de régimen común”, op. cit., pág. 27). En igual sentido, Libro verde. Los gobiernos locales intermedios (op. cit., págs. 110-111).

83 Es el caso de G. FERNÁNDEZ FARRERES, "Qué hacer con las diputaciones provinciales (Presupuestos y límites constitucionales para su reforma)", op. cit., pág. 100.

84 En tal sentido, pueden verse las consideraciones de S. MARTíN-RETORILLO (La provincia. Pasado, presente y futuro, op. cit., pág. 83) y F. LÓPEZ RAMÓN (“Los servicios públicos propios de la provincia”, R. GÓMEZ-FERRER MORANT (dir.), La provincia en el sistema constitucional. págs. 356-357, 1991, Madrid: Civitas) o, en tiempos más recientes, las de J. M. CARBONERO GALLARDO (“El nuevo papel de las diputaciones provinciales", op. cit., pág. 260, autor que, con anterioridad, se había manifestado en contra de esta posibilidad, "La provincia de régimen común", op. cit., págs. 48-49), J. L. RIVERO YSERN ("El régimen local en el nuevo Estatuto de Autonomía. Reglas sustantivas y distribución de competencias", S. MUÑOZ MACHADO y R. REBOLLO PUIG (dirs.), Comentarios al Estatuto de Autonomía de Andalucía, pág. 861, 2008, Madrid: Civitas-Thomson), E. CARBONELL PORRAS (“¿Existe un criterio sobre las diputaciones provinciales? Algunas reflexiones sobre la provincia en Andalucía”, op. cit., págs. 190-191), R. JIMÉNEZ ASENSIO (“Diputaciones provinciales: ¿tiempo de prórroga?”, Revista Democracia y Gobierno Local, núm. 35, 2016, pág. 11) o A. BAYONA I ROCAMORA ("El orden constitucional actual: limitaciones, condicionantes y posibilidades de reforma de las diputaciones provinciales", El futuro de la Administración local y el papel de los Gobiernos locales intermedios, op. cit., págs. 45-50).

Así se ha defendido también por la FEMP ("Propuestas de la Comisión de Diputaciones Provinciales, Cabildos y Consejos Insulares de la Federación Española de Municipios y provincias sobre Fortalecimiento institucional y modernización de las diputaciones, cabildos y consejos insulares y demás entidades locales intermedias" de 10 de abril de 2012) y por la Fundación Democracia y Gobierno Local (Libro verde. Los Gobiernos locales intermedios, op. cit., págs. 111-129 y 188-189).

85 Es el caso, como ya vimos, de comarcas y áreas metropolitanas. En tal sentido puede verse el Capítulo II de la Ley 1/1991, de 14 de marzo, de creación de la comarca del Bierzo, el Título III del Decreto Legislativo 1/2006, del Texto Refundido de la Ley de comarcalización de Aragón, o los Títulos II y III de la Ley 31/2010, de 3 agosto, del Área metropolitana de Barcelona. 
«el carácter residual y excepcional» de las competencias materiales que pudieran atribuírseles ${ }^{86}$, o sí, y todo apunta en principio a qué es posible, otra cosa es que exista voluntad política en tal sentido, cabe avanzar en esta línea, como mantienen otros muchos autores y han reivindicado recientemente las propias diputaciones en la declaración institucional sobre «el papel de los gobiernos provinciales en el equilibrio territorial: Entre la despoblación rural y la concentración urbana», efectuada por la "IV Conferencia de Presidentes de Gobiernos Provinciales", celebrada en Granada en febrero de 201987. Si es así, habría, y ahí está el verdadero reto, que identificar las «materias concretamente supramunicipales» ${ }^{88}$, los «intereses propios» del espacio provincial, base imprescindible para la determinación de esas posibles competencias. Aunque contamos ya con las concreciones efectuadas por diferentes autores ${ }^{89}$, así como con las formuladas por la Comisión de diputaciones provinciales, cabildos y consejo insulares de la FEMP o por la Fundación Democracia y Gobierno Local ${ }^{90}$, hay que reconocer, no obstante, que la determinación de los intereses propios de la provincia y la delimitación de las materias y competencias que respecto de ellos podrían asumir las diputaciones, constituye una tarea compleja -habría que aclarar además cuál es el legislador competente ${ }^{91}$, pero que, quizás, merezca la pena abordar si se quiere verdaderamente reordenar el nivel de gobierno supramunicipal. Para la fijación de estas competencias, podrían explorarse las posibilidades ofrecidas por el examen de la escala territorial adecuada para la prestación de los distintos servicios públicos locales, su nivel óptimo de prestación. Nuestro ordenamiento puede considerarse muy deficitario en este sentido, pues no ha contado nunca con reglas generales que permitan determinar a quién corresponde fijar esos ámbitos territoriales y de acuerdo con qué principios o criterios ha de hacerse ${ }^{92}$, teniendo en cuenta además que han de ser, por definición, variables al depender, entre otros factores, del objeto de cada servicio, de las características del territorio en el que se presten o del nivel y distribución de la población en el mismo ${ }^{93}$. Por ello, y en la línea ya apuntada por M. BASSOLS ${ }^{94}$, F. LÓPEZ RAMÓN o J. J. DÍEZ SÁNCHEZ ${ }^{95}$, cabría valorar la posibilidad

86 "Qué hacer con las diputaciones provinciales (Presupuestos y límites constitucionales para su reforma)", op. cit., pág. 83.

87 En su apartado 3, concretamente, puede leerse: «Afirmamos la necesidad de la existencia de un nivel intermedio en el Gobierno local que complemente el municipal. Reivindicamos que el legislador, teniendo en cuenta las peculiaridades del mundo local, remueva los obstáculos normativos que dificultan la labor de los Gobiernos locales intermedios y que les atribuya competencias en cantidad y calidad suficientes, a título de competencias propias, de manera que estén efectivamente en condiciones de poder decidir y poner en práctica políticas propias».

El texto de la declaración puede encontrarse en la Revista Democracia y Gobierno Local, núm. 44, 2019, págs. 18-21.

88 En términos de F. GARCÍA RUBIO, "Las entidades supramunicipales en el Gobierno local español. Reflexiones tras la reforma de la sostenibilidad”, Cuadernos de Derecho Local (QDL), núm. 34, 2014, pág. 181.

89 Así con las de R. PARADA (“La segunda descentralización. Del Estado autonómico al municipal”, págs. 54-62, 2007, Cizur Menor: Thomson-Civitas), A. SÁNCHEZ BLANCO (Organización intermunicipal, op. cit., pág. 99), L. COSCULLUELA ("El debate sobre la abolición de la provincia y la reforma de las diputaciones", op. cit., págs. 50-51), V. MERINO ESTRADA ("Las competencias de la provincia como entidad local", El futuro de la Administración local y el papel de los Gobiernos locales intermedios, op. cit., págs. 420432 y 440-443) o L. PAREJO que si, en un tiempo anterior, había mantenido «la imposibilidad de una diferenciación neta y sustantiva» entre «intereses municipales y/o provinciales» ("La provincia como entidad local determinada por la agrupación de municipios: Fines básicos y competencias mínimas”, La provincia en el sistema constitucional, op. cit., pág. 9), va a señalar en 2016 que «desde el punto de vista funcional» procede «la superación de la actual coincidencia sustancial de los círculos de intereses de ambos escalones locales (diferenciados solo por el criterio de la municipalidad-supramunicipalidad) y la consecuente atribución de un elenco propio de competencias, si bien sin reconocimiento de una capacidad universal (por reserva exclusiva de la potencia creativa del escalón municipal)» ("El porvenir a la luz de los condicionantes de la actual coyuntura, del escalón supramunicipal de la Administración local”, op. cit., pág. 2).

90 Expuestas, respectivamente, en Propuestas de la Comisión de Diputaciones Provinciales, Cabildos y Consejos Insulares de la Federación Española de Municipios y provincias: Fortalecimiento institucional y modernización de las diputaciones, cabildos y consejos insulares y demás entidades locales intermedias de 10 de abril de 2012; y en el Libro verde. Los Gobiernos locales intermedios (op. cit., págs. 111-119).

91 Cuestión sobre la que tampoco existe consenso en la doctrina. En términos favorables a la competencia del legislador estatal pueden verse las consideraciones de M. ALMEIDA CERRADA ("La reforma de la planta local, estructura competencial, organización y articulación de la Administración local”, op. cit., págs. 102-105). En sentido contrario, las de F. VELASCO CABALLERO y C. VIVER i PI-SUNYER ("Competencias para la reforma de la planta local", Elementos para un debate sobre la reforma institucional de la planta local en el Estado autonómico, op. cit., pág. 152).

92 Por ello, lo habitual, como señala M. VAQUER, es que la decisión sobre «el interés municipal, comarcal, provincial o supralocal» de un concreto servicio o actividad haya quedado «en manos de la inercia histórica, de la capacidad de gasto de cada Gobierno territorial y de la competencia entre ellos en ejercicio de su autonomía política» ("Gobiernos locales intermedios y prestación de servicios locales", Cuadernos de Derecho Local (QDL), núm. 29, 2012, pág. 150).

93 Sobre los criterios a utilizar en la delimitación de estos espacios pueden verse, entre otras, las aportaciones de M. VAQUER CABALLERÍA ("Gobiernos locales intermedios y prestación de servicios locales”, op. cit., págs. 150-151) o M. ARENILLA SÁEZ (EI pequeño municipio: núcleo democrático vs. Prestación de servicios”, pág. 201 y ss.).

94 "Las diputaciones provinciales a los diez años de la Ley reguladora de las bases del régimen local: Experiencias y perspectivas", op. cit., págs. 462-465.

95 "Estrategias para ganar tamaño en la gestión administrativa tras la reforma local de 2013”, op. cit., págs. $160-162$. 
de actuar, en términos del segundo de estos autores, «uniendo los poderes de organización del territorio con los de ordenación del mismo» ${ }^{96}$. La determinación de la escala territorial adecuada para el ejercicio de cada competencia, para la prestación de cada servicio, puede considerarse un presupuesto especialmente idóneo para la decisión sobre la entidad: el municipio, la diputación u otro ente de similar naturaleza, que debería asumir su prestación; e, incluso, para aislar los supuestos en los que pudiera resultar conveniente una fusión de municipios ${ }^{97}$ o simples fórmulas de colaboración que no impliquen la creación de nuevos entes ${ }^{98}$.

Una eventual reforma de la LBRL con el objetivo de una mejor articulación del nivel supramunicipal de gobierno del territorio, debería también plantearse una delimitación más precisa del papel de las distintas entidades que lo componen. Es cierto que ya la LBRL de 1985 ofrecía una definición de cada una de ellas y que ha sido, en buena medida, por obra del ordenamiento autonómico y la actuación de la Administración autonómica por lo que el modelo legal se ha visto distorsionado. Ahora bien, siendo así, quizás sea aconsejable una reforma legal que deje establecida con una mayor precisión la función, el papel que cada una de esas entidades ha de cumplir, si es no se desea, como hoy ocurre, que sean intercambiables, qué entidades distintas con regímenes diferentes valgan para satisfacer los mismos cometidos. Las frecuentes alusiones de la doctrina a la necesidad de "repensar el sentido y magnitud de todas estas fórmulas» ${ }^{99}$, de deslindar «la propia razón de existir» de las distintas entidades que integran la «planta local» ${ }^{100}$, dado que si «no presentan rasgos diferenciales y aparecen como entidades indistintas, la duplicidad y la ineficiencia provocarán desorientación, y privarán de justificación a una necesidad estructural» ${ }^{101}$, da cuenta, en efecto, de un estado de opinión crítico con la situación actual, pero en el que es más difícil, sin embargo, encontrar propuestas concretas sobre el sentido y alcance de una posible reforma legal. Desde luego, han de reconocerse las dificultades que el empeño conlleva, pues a la falta de criterios constitucionales que permitan diferenciar entre las distintas entidades que pueden situarse en ese nivel intermedio de gobierno entre Comunidades Autónomas y municipios, debe añadirse la duda, siempre presente, sobre el alcance de la competencia del legislador básico estatal en la materia ${ }^{102}$. No obstante, la Ley de 1985 ya las reguló, el problema es que sus disposiciones en la materia quizás no fueran lo suficiente precisas o, por lo menos, no han servido para situar el desarrollo de la supramunicipalidad sobre bases que conduzcan a un modelo más racional del que finalmente se ha implantado. Es, por ello, que cabe exigir al legislador un mayor esfuerzo en la definición del cometido propio de cada entidad, distinguiendo entre aquellas surgidas del derecho de asociación de los municipios y las que son el resultado de la institucionalización por las Comunidades Autónomas de un nivel propio de gobierno, esfuerzo que ha de alcanzar a la correcta delimitación de las funciones de cada una de ellas en relación con la entidad provincial ${ }^{103}$.

96 "Políticas ante la fragmentación del mapa municipal" (Revista de Estudios de la Administración Local y Autonómica, núm. 313314, 2010, pág. 100). El autor ya había examinado, en 1991, la «escasa presencia de la Provincia en la Ordenación del territorio», afirmación que puede seguir suscribiéndose ("Los servicios públicos propios de la provincia", op. cit., págs. 359-365).

97 En tal sentido M. VAQUER, "Gobiernos locales intermedios y prestación de servicios locales", op. cit., pág. 153.

98 Una posibilidad que para autores como J. I. MARTÍNEZ GARCÍA debería potenciarse ("Diez tesis sobre organización territorial", Revista de Estudios Locales, núm. 186, 2015, pág. 570) o, al menos, no descartarse (C. ESCUIN PALOP, "Algunas reflexiones sobre la Administración local", Memorial para la reforma del Estado. Estudios en homenaje al profesor Santiago Muñoz Machado, vol. II, op. cit., págs. 1.990-1.992). Al respecto puede verse también el estudio de E. CARBONELL PORRAS, "La cooperación intermunicipal en la realización de las obras y los servicios locales (reflexiones a propósito de algunos mecanismos distintos de la creación de entidades supramunicipales)", Anuario de Derecho Municipal, 2010, págs. 57 y ss.

99 J. J. DÍEZ SÁNCHEZ, "Estrategias para ganar tamaño en la gestión administrativa tras la reforma local de 2013 ", op. cit., pág. 158.

100 F. VELASCO CABALLERO, "La planta local en España: criterios para la toma de decisiones", op. cit., pág. 31.

101 J. LÓPEZ-MEDEL BASCONES y M. ZAFRA VÍCTOR, "Análisis del papel y funciones de los Gobiernos locales intermedios: propuestas de articulación", op. cit., pág. 266.

102 Sobre el alcance de competencias estatales y autonómicas en la materia, me remito a lo expuesto, entre otros, por F. FERNÁNDEZ FARRERES ("Qué hacer con las diputaciones provinciales (Presupuestos y límites constitucionales para su reforma", op. cit., págs. 78-81).

103 En este sentido, puede destacarse el reciente esfuerzo realizado por L. PAREJO de «fijación de las líneas de solución (en el marco legal básico)» para la necesaria racionalización del nivel de gobierno supramunicipal y la debida articulación entre la provincia y el resto de entidades que lo componen, proponiendo «la previsión de la intervención de la provincia en los procedimientos autonómicos de creación, modificación o supresión o disolución de comarcas u otras entidades determinadas por la agrupación de municipios, y la potenciación (con traducción de competencias) de las tareas provinciales de colaboración, cooperación y, especialmente, coordinación de la gestión de intereses locales supramunicipales encomendadas a dichas entidades, así como de la colaboración y cooperación en asuntos de interés común con las áreas metropolitanas». También considera que podría resultar conveniente «imponer a las diputaciones la acción concentrada o, incluso, descentralizada» en comarcas u otras entidades infraprovinciales «de las actividades cuya lógica lo hiciera pertinente». Finalmente, «la introducción de un informe provincial determinante» en los procedimientos de creación, modificación o supresión de mancomunidades u otras organizaciones asociativas municipales «y el reforzamiento de las competencias de coordinación ya asignadas respecto de los servicios prestados por dichas entidades», así como la «delegación directa de competen- 
Ahora bien, el que el legislador estatal pueda, y deba, contribuir a la reconducción de la situación actual, no puede hacernos olvidar que la consecución de ese reto pasa, en buena medida, por las Comunidades Autónomas que tienen en sus manos la decisión sobre la vertebración de su territorio a partir de la creación de circunscripciones territoriales propias y son las competentes para la fijación de su régimen jurídico. No cabe olvidar que, en muchos casos, han sido ellas las que han legislado en términos que han contribuido decididamente a la contestada situación a la que hemos llegado y las que tienen que proceder, a nivel interno, a la clarificación de la situación. A ellas corresponde pues, dentro del respeto al ordenamiento básico estatal, precisar la función de las distintas entidades que en su ámbito integran el nivel de gobierno local y establecer un modelo de relación entre ellas, y con la provincia, racional y coherente, pues es claro que «un sistema complejo solamente es viable si se realiza una distribución de los cometidos entre las unidades que lo integran» ${ }^{104}$. Iniciativas como la fallida Proposición de Ley de Distribución de responsabilidades administrativas entre las entidades locales aragonesas presentada en las Cortes de Aragón en 2014 parecen apuntar en la dirección adecuada ${ }^{105}$.

Ante una posible reordenación del nivel intermedio de gobierno local no debería olvidarse el flanco representado por la relación de las entidades que lo componen con las Comunidades Autónoma. Un debate prácticamente olvidado desde que, muy pronto, la Administración autonómica lograra imponer y consolidar una estructura periférica en clara oposición a los intentos, a los que ganarán la partida, de utilización de las diputaciones como entes para la gestión ordinaria de las competencias autonómicas. Una posibilidad, sin embargo, que sigue contando con reconocimiento legal aunque ciertamente los vientos no soplen en esa dirección ${ }^{106}$.

En definitiva, mientas la Constitución no se modifique y pueda establecerse, en su caso, un nuevo modelo de organización supramunicipal, no cabe más que reivindicar, tanto del legislador estatal como del autonómico, aquellas modificaciones que coadyuven a una mejor articulación del sistema, lo que es probable que pase por una reconsideración de las competencias de las diputaciones respecto de todos los municipios, pues todos ellos forman hoy parte de la provincia, así como por la clarificación de «la propia razón de existir» de las distintas entidades que «integran la "planta local"» ${ }^{107}$, poniendo fin a la confusión existente. L. PAREJO ha apuntado recientemente, y aportaciones de esta naturaleza han de ser bienvenidas, que «la racionalización que procede» es «la que i) descansa en la posición institucional prevalente que, por evidente decisión constitucional, debe reconocerse a la provincia en el escalón de la gestión de los intereses locales desbordantes del horizonte municipal, y ii) se inscribe en la lógica de la colaboración, cooperación y coordinación interadministrativas desde los valores de la solidaridad territorial y la cohesión social, pero iii) debe respetar los límites que resultan de la competencia legislativa autonómica y el derecho de asociación del municipio garantizado en la Carta Europea de la Autonomía Local» ${ }^{108}$. Desde luego, es claro que cualquier reforma normativa en una materia tan trascendente y sensible deberá ir acompañada de un debate político serio y de los consensos necesarios entre las distintas fuerzas políticas. Aunque las circunstancias presentes no inviten precisamente al optimismo, hay que mantener la confianza de que, entre todos, seamos capaces de responder al reto que hoy representa una adecuada articulación del nivel intermedio de gobierno local. Como ya ha indicado F. DELGADO PIQUERAS «no se puede negar la conveniencia de una reforma del título VIII de la Constitución», pero «mientras tanto, tampoco se pueden dejar de acometer reformas legales, por más que resolver este debate parezca "la cuadratura del círculo". Ese problema matemático, en apariencia insoluble, en realidad lo era para los griegos clásicos, que solo usaban la regla y el compás. Pero dejó de serlo en cuanto se descubrió la constante "pi"»" 109.

cias en los municipios sea por la Administración del estado, sea por la autonómica (con posible condicionamiento de tal operación a la apreciación, debidamente motivada, de preferencia a la delegación en la propia provincia)» ("Algunas reflexiones sobre posibles líneas maestras de arreglo de la provincia y la diputación peninsulares de régimen común”, op. cit., págs. 26-27).

104 A. GALÁN GALÁN, "La provincia como parte de un sistema de Administraciones Públicas. La necesaria articulación competencial”, El futuro de la Administración local y el papel de los Gobiernos locales intermedio, op. cit., pág. 408.

105 Boletín Oficial de las Cortes de Aragón. Número 250. 18 de julio de 2014.

106 Al respecto pueden verse, entre otras, las consideraciones de T. DE LA CUADRA SALCEDO ("El debate sobre las diputaciones en un escenario de reforma constitucional del Título VIII", op. cit., págs. 3-5). Años antes, M. BASSOLS, en un conjunto de reflexiones de plena vigencia, abogaba por «una actualización del propio contenido del Régimen local», en especial, «en la faceta que afecta a sus conexiones y relaciones con las Comunidades Autónomas» ("Las diputaciones provinciales a los diez años de la Ley Reguladora de las Bases del Régimen Local: Experiencias y perspectivas”, op. cit., págs. 456-457).

107 F. VELASCO CABALLERO, "La planta local en España: criterios para la toma de decisiones", op. cit., pág. 31.

108 "Algunas reflexiones sobre posibles líneas maestras de arreglo de la provincia y la diputación peninsulares de régimen común”, op. cit., pág. 26.

109 "La provincia en las comunidades autónomas pluriprovinciales, su compatibilidad con la comarca y otras nuevas administraciones", Documentación Administrativa (DA), núm. 3, 2016, pág. 15. 
DA. Nueva Época - N. ${ }^{\circ}$ 6, enero-diciembre 2019 - ISSN: 1989-8983 - DOI: 10.24965/da.i6.10765 - [Págs. 81-102]

De nuevo sobre el nivel intermedio de gobierno local ¿Qué cabe hacer sin reformar la constitución?

Concepción Barrero Rodríguez

\section{REFERENCIAS BIBLIOGRÁFICAS}

ALMEIDA CERRADA, M. (2013): "La reforma de la planta local, estructura competencial, organización y articulación de la Administración local”, en DÍEZ SÁNCHEZ, J. J. (coord.): La planta del Gobierno Local: actas del VIII Congreso de la Asociación Española de Profesores de Derecho Administrativo, pág. 100-105. Alicante, 8 y 9 de febrero de 2013. Madrid: Asociación española de Profesores de Derecho Administrativo-Fundación Democracia y Gobierno Local.

ARENILLA SÁEZ, M. (2012): "El pequeño municipio: núcleo democrático vs. prestación de servicios", en Documento Técnico. Elementos para un debate sobre la reforma institucional de la planta local en el Estado autonómico, págs. 193-214. Madrid: Fundación Democracia y Gobierno Local. URL: https://www.gobiernolocal.org/elementospara-un-debate-sobre-la-reforma-institucional-de-la-planta-local-en-el-estado-autonomico-2/.

BAÑO LEÓN, J. M. ${ }^{a}$ (coord.) (2016): Memorial para la reforma del Estado: estudios en homenaje al Profesor Santiago Muñoz Machado, vol. 2, pág. 2.006. Madrid: Centro de Estudios Políticos y Constitucionales (CEPC).

BARRERO RODRÍGUEZ, C. (2015): "La prestación de los servicios municipales mínimos en el nuevo artículo 26 de la LBRL. La difícil interpretación de un precepto fundamental", en Revista Española de Derecho Administrativo, núm. 170 , págs. 21 y ss.

BASSOLS COMA, M. (1996): "Las diputaciones provinciales a los diez años de la Ley Reguladora de las Bases del Régimen Local: Experiencias y perspectivas", en La provincia en el Estado de las autonomías, págs. 456-465. Madrid: Diputación de Barcelona-Marcial Pons.

BAYONA I ROCAMORA, A. (2017): "El orden constitucional actual: limitaciones, condicionantes y posibilidades de reforma de las diputaciones provinciales", en PAREJO ALFONSO, L. (dir.) y ARROYO GIL, A. (coord.): EI futuro de la Administración local y el papel de los Gobiernos locales intermedios, págs. 45-52. Madrid: Fundación Democracia y Gobierno Local.

BEATO ESPEJO, M. (1996): "Las diputaciones provinciales del territorio de la Comunidad Autónoma de Extremadura, a los diez años de vigencia de la Ley Reguladora de las Bases del Régimen Local”, en La provincia en el Estado de las autonomías, págs. 260-261. Madrid: Diputación de Barcelona-Marcial Pons.

CARBALLEIRA RIVERA, M. ${ }^{a}$ (1993): La provincia en el sistema autonómico español, págs. 23-75. Madrid: Marcial Pons.

CARBONELL PORRAS, E. (2010): "La cooperación intermunicipal en la realización de las obras y los servicios locales. (Reflexiones a propósito de algunos mecanismos distintos de la creación de entidades supramunicipales)", en Anuario de Derecho Municipal 2010, núm. 4, págs. 57-96. URL: https://repositorio.uam.es/handle/10486/664366.

CARBONELL PORRAS, E. (2012): “¿Existe un criterio sobre las diputaciones provinciales? Algunas reflexiones sobre la provincia en Andalucía”, en COSCULLUELA MONTANER, L.; MEDINA ALCOZ, L. (dirs.) y HERNANDO RYDINGS, M. (coord.): Crisis económica y reforma del régimen local, pág. 190-191. Cizur Menor (Navarra): Civitas-Thomson Reuters.

CARBONELL PORRAS, E. (2016): "Replanteamiento sobre las provincias: del pretendido reforzamiento de su posición institucional a una posible mutación constitucional”, en Anuario del Gobierno Local 2015/2016, págs. 124125. Madrid: Fundación Democracia y Gobierno Local.

CARBONERO GALLARDO, J. M. (2005): "La provincia de régimen común”, en CARBONERO GALLARDO, J. M. (dir.): La intermunicipalidad en España, págs. 48-49. Madrid: Ministerio de Administraciones Públicas (MAP).

CARBONERO GALLARDO, J. M. (2014): "EI nuevo papel de las Diputaciones provinciales", en CARRILLO DONAIRE, J. A. y NAVARRO RODRÍGUEZ, P. (coord.): La reforma del Régimen Jurídico de la Administración Local. El nuevo marco regulatorio a la luz de la Ley de Racionalización y Sostenibilidad de la Administración Local, pág. 260. Madrid: El Consultor de los Ayuntamientos.

CARRO FERNÁNDEZ-VALMAYOR, J. L. (2004): "La Administración local en el espacio autonómico", en Congreso Internacional Municipia Siglo XXI. Ciudadanía y Gobierno Local, págs. 12-13. Zaragoza, 1-3 de diciembre del 2004. URL: http://old.dpz.es/diputacion/areas/presidencia/asistencia-municipios/municipia/congreso/ponencias. htm.

CARRO FERNÁNDEZ-VALMAYOR, J. L. (2016): "Articulación organizativa y Estado compuesto”, en Documentación Administrativa (DA), núm. 3, págs. 6-15. DOI: https://doi.org/10.24965/da.v0i3.10369.

CASTILLO BLANCO, F. (2016): "La reforma de los gobiernos locales en España: ¿Una oportunidad perdida para lograr una planta local competitiva y sostenible?", en BAÑO LEÓN, J. M. ${ }^{a}$ (coord.): Memorial para la reforma del Estado: estudios en homenaje al Profesor Santiago Muñoz Machado, vol. 2, págs. 1.972-1.973. Madrid: Centro de Estudios Políticos y Constitucionales (CEPC).

CLAVERO ARÉVALO, M. F. (1985): "La Provincia ante una encrucijada histórica en el ciento cincuenta aniversario de su creación (1833-1893)", en La Provincia: IX Congreso Italo-Español de Profesores de Derecho Administrativo, pág. 245, 1984. Granada: Departamento de Derecho Administrativo de la Universidad de Granada.

COSCULLUELA MONTANER, L. (2011): "El debate sobre la abolición de la provincia y la reforma de las diputaciones", en Anuario del Gobierno local 2011, págs. 50-67. Madrid: Fundación Democracia y Gobierno Local. URL: http://repositorio.gobiernolocal.es/xmlui/handle/10873/1248. 
DA. Nueva Época - N. ${ }^{\circ}$ 6, enero-diciembre 2019 - ISSN: 1989-8983 - DOI: 10.24965/da.i6.10765 - [Págs. 81-102]

De nuevo sobre el nivel intermedio de gobierno local ¿Qué cabe hacer sin reformar la constitución?

Concepción Barrero Rodríguez

COSCULLUELA MONTANER, L. (2012): "Problemática de la Provincia como entidad local", en COSCULLUELA MONTANER, L.; MEDINA ALCOZ, L. (dirs.) y HERNANDO RYDINGS, M. (coord.): Crisis económica y reforma del régimen local, págs. 122-124. Cizur Menor (Navarra): Civitas-Thomson Reuters.

D' ANJOU GONZÁLEZ, J. (1994): Las Mancomunidades intermunicipales en el Régimen local español. Antecedentes, situación actual y catálogo de las mismas, págs. 19-20. Madrid: Ministerio de Administraciones Públicas (MAP).

DE LA CUADRA-SALCEDO FERNÁNDEZ DEL CASTILLO, T. (2016): "El debate sobre las diputaciones en un escenario de reforma constitucional del Título VIII”, en Documentación Administrativa (DA), núm. 3, págs. 3-19. DOI: $h$ ttps://doi.org/10.24965/da.v0i3.10370.

DELGADO PIQUERAS, F. (2016): "La provincia en las comunidades autónomas pluriprovinciales, su compatibilidad con la comarca y otras nuevas administraciones”, en Documentación Administrativa (DA), núm. 3, pág. 15. DOI: https://doi.org/10.24965/da.v0i3.10373.

DÍEZ SÁNCHEZ, J. J. (2015): "Estrategias para ganar tamaño en la gestión administrativa tras la reforma local de 2013", en BOIX PALOP, A. y DE LA ENCARNACIÓN, A. M. a (coord.): Retos del Gobierno Local tras la reforma de 2013, págs. 157-162. Cizur Menor (Navarra): Thomson Reuters-Aranzadi.

EMBID IRUJO, A. (2012): "Reforma de la planta municipal y prestación de servicios locales", en Cuadernos de Derecho Local (QDL), núm. 29, pág. 102. URL: http://repositorio.gobiernolocal.es/xmlui/handle/10873/1292.

ESCRIBANO COLLADO, P. (2016): "Provincias y diputaciones: Una polémica sin proyecto institucional”, en BAÑO LEÓN, J. M. a (coord.): Memorial para la reforma del Estado: estudios en homenaje al Profesor Santiago Muñoz Machado, vol. 2, págs. 1.995-2.017. Madrid: Centro de Estudios Políticos y Constitucionales (CEPC).

ESCUIN PALOP, C. (2016): "Algunas reflexiones sobre la Administración local”, en BAÑO LEÓN, J. M. ${ }^{\text {a }}$ (coord.): Memorial para la reforma del Estado: estudios en homenaje al Profesor Santiago Muñoz Machado, vol. 2, págs. 1.990-1.992. Madrid: Centro de Estudios Políticos y Constitucionales (CEPC).

FERNÁNDEZ FARRERES, G. (2017): "Qué hacer con las diputaciones provinciales (Presupuestos y límites constitucionales para su reforma)", en PAREJO ALFONSO, L. (dir.) y ARROYO GIL, A. (coord.): El futuro de la Administración local y el papel de los Gobiernos locales intermedios, págs. 78-101. Madrid: Fundación Democracia y Gobierno Local.

FERNÁNDEZ-FIGUEROA GUERRERO, F. (2017): "De la «cooperación» en el plan provincial de cooperación a las obras y servicios municipales a la «concertación» en otros instrumentos de planificación", en PAREJO ALFONSO, L. (dir.) y ARROYO GIL, A. (coord.): El futuro de la Administración local y el papel de los Gobiernos locales intermedios, págs. 460-476. Madrid: Fundación Democracia y Gobierno Local.

FERREIRA FERNÁNDEZ, A. J. (1999): Régimen jurídico de la Comarca en el sistema autonómico español, pág. 280. Barcelona: Cedecs.

FONT I LLOVET, T. (1992): “Aproximación a la estructura de la Administración local en España”, en FONT I LLOVET, T. (coord.): Informe sobre Gobierno Local, pág. 29. Madrid: Ministerio para las Administraciones Públicas-Fundació Carles Pi i Sunyer d'Estudis Autonòmics i Locals.

FONT I LLOVET, T. (2011): “Uniformidad y diferenciación en las instituciones autonómicas y locales en España: Aquiles y la tortuga”, en LÓPEZ MENUDO, F. (dir.): Derechos y Garantías del ciudadano. Estudios en homenaje al Profesor Alfonso Pérez Moreno, pág. 1.234. Madrid: lustel.

FONT I LLOVET, T. (2016): "Los retos actuales del Gobierno local: Repolitización, diversificación, interiorización" en BAÑO LEÓN, J. M. a (coord.): Memorial para la reforma del Estado: estudios en homenaje al Profesor Santiago Muñoz Machado, vol. 2, págs. 1.937-1.938. Madrid: Centro de Estudios Políticos y Constitucionales (CEPC).

FUNDACIÓN DEMOCRACIA Y GOBIERNO LOCAL (2011): Libro verde. Los Gobiernos locales intermedios en España. Diagnóstico y propuestas para reforzar el valor institucional de las diputaciones provinciales y de los demás gobiernos locales intermedios en el Estado autonómico, pág. 76-189. Madrid: Fundación Democracia y Gobierno Local. URL: https://repositorio.gobiernolocal.es/xmlui/handle/10873/772.

GALÁN GALÁN, A. (2017): "La provincia como parte de un sistema de Administraciones Públicas. La necesaria articulación competencial”, en PAREJO ALFONSO, L. (dir.) y ARROYO GIL, A. (coord.): El futuro de la Administración local y el papel de los Gobiernos locales intermedios, págs. 408. Madrid: Fundación Democracia y Gobierno Local.

GARCÍA DE ENTERRÍA, E. (1981): Informe de la Comisión de expertos sobre Autonomías. Madrid: Centro de Estudios Constitucionales.

GARCÍA RUBIO, F. (2014): "Las entidades supramunicipales en el Gobierno local español. Reflexiones tras la reforma de la sostenibilidad”, en Cuadernos de Derecho Local (QDL), núm. 34, pág. 181. URL: http://repositorio. gobiernolocal.es/xmlui/handle/10873/1533.

GIFREU I FONT, J. (2017): "La atomización de la planta municipal y sus repercusiones en la prestación eficiente de los servicios mínimos obligatorios: la operatividad de la función coordinadora de las diputaciones provinciales", en PAREJO ALFONSO, L. (dir.) y ARROYO GIL, A. (coord.): El futuro de la Administración local y el papel de los Gobiernos locales intermedios, págs. 131-214. Madrid: Fundación Democracia y Gobierno Local.

JIMÉNEZ ASENSIO, R. (2016): “Diputaciones provinciales: ¿tiempo de prórroga?”, en Revista Democracia y Gobierno Local, núm. 35, pág. 11. URL: https://www.gobiernolocal.org/revista-democracia-y-gobierno-local-no-35/.

LÓPEZ RAMÓN, F. (1991): "Los servicios públicos propios de la provincia”, en GÓMEZ-FERRER MORANT, R. (dir.): La provincia en el sistema constitucional, págs. 356-365. Madrid: Civitas. 
DA. Nueva Época - N. ${ }^{\circ}$ 6, enero-diciembre 2019 - ISSN: 1989-8983 - DOI: 10.24965/da.i6.10765 - [Págs. 81-102]

De nuevo sobre el nivel intermedio de gobierno local ¿Qué cabe hacer sin reformar la constitución?

Concepción Barrero Rodríguez

LÓPEZ RAMÓN, F. (2010): "Políticas ante la fragmentación del mapa municipal", en Revista de Estudios de la Administración Local y Autonómica (REALA), núm. 313-314, pág. 100. DOI: https://doi.org/10.24965/reala.vi313314.9923.

LÓPEZ RODÓ, L. (1985): "La Provincia en las Comunidades Autónomas uniprovinciales y en Canarias", en La Provincia: IX Congreso Italo-Español de Profesores de Derecho Administrativo, pág. 395-403. Granada, 1984. Granada: Departamento de Derecho Administrativo de la Universidad de Granada.

LÓPEZ-MEDEL BASCONES, J. y ZAFRA VICTOR, M. (2012): "Análisis del papel y funciones de los Gobiernos locales intermedios: propuestas de articulación”, en FUNDACIÓN DEMOCRACIA Y GOBIERNO LOCAL: Documento Técnico. Elementos para un debate sobre la reforma institucional de la planta local en el Estado autonómico, págs. 250-282. Madrid: Fundación Democracia y Gobierno Local. URL: https://www.gobiernolocal. org/elementos-para-un-debate-sobre-la-reforma-institucional-de-la-planta-local-en-el-estado-autonomico-2/.

MARTÍNEZ GARCÍA, J. I. (2015): "Diez tesis sobre organización territorial", en Revista de Estudios Locales. Cunal, núm. 181, pág. 570.

MARTÍN-RETORTILLO, S. (1991): La Provincia. Pasado, presente y futuro. Madrid: Civitas.

MERINO ESTRADA, V. (2017): "Las competencias de la provincia como entidad local", en PAREJO ALFONSO, L. (dir.) y ARROYO GIL, A. (coord.): El futuro de la Administración local y el papel de los Gobiernos locales intermedios, págs. 420-443. Madrid: Fundación Democracia y Gobierno Local.

MORALES MATO, G. y MÉNDEZ GARCÍA, B. (2017): "Despoblación rural, comarcas y áreas metropolitanas en España”, en PAREJO ALFONSO, L. (dir.) y ARROYO GIL, A. (coord.): El futuro de la Administración local y el papel de los Gobiernos locales intermedios, págs. 125. Madrid: Fundación Democracia y Gobierno Local.

PARADA VÁZQUEZ, J. R. (2007): La segunda descentralización. Del Estado autonómico al municipal, págs. 54-62. Cizur Menor (Navarra): Thomson-Civitas.

PAREJO ALFONSO, L. (1991): "La provincia como entidad local determinada por la agrupación de municipios: Fines básicos y competencias mínimas”, en GÓMEZ-FERRER MORANT, R. (dir.): La provincia en el sistema constitucional, págs. 9. Madrid: Civitas.

PAREJO ALFONSO, L. (2012): "Apuntes para el debate sobre la planta y la articulación interna de la Administración local”, en Cuadernos de Derecho Local (QDL), núm. 29, pág. 20. URL: http://repositorio.gobiernolocal.es/xmluil handle/10873/1285.

PAREJO ALFONSO, L. (2016): “¿Tiene futuro la provincia como entidad local intermedia?”, en Revista Democracia y Gobierno Local, núm. 34, pág. 5-9. URL: https://www.gobiernolocal.org/revista-democracia-y-gobierno-local-no-34/.

PAREJO ALFONSO, L. (2016): "El porvenir a la luz de los condicionantes de la actual coyuntura, del escalón supramunicipal de la Administración local”, en Cuadernos de Derecho Local (QDL), núm. 40, págs. 2-28. URL: http://repositorio.gobiernolocal.es/xm/ui/bitstream/handle/10873/1701/03_PAREJO_P12_37_QDL_40.pdf.

PAREJO ALFONSO, L. (2017): "Algunas reflexiones sobre posibles líneas maestras de arreglo de la provincia y la diputación peninsulares de régimen común”, en PAREJO ALFONSO, L. (dir.) y ARROYO GIL, A. (coord.): EI futuro de la Administración local y el papel de los Gobiernos locales intermedios, pág. 17-27. Madrid: Fundación Democracia y Gobierno Local.

RIVERO YSERN, J. L. (2008): "El régimen local en el nuevo Estatuto de Autonomía. Reglas sustantivas y distribución de competencias", en MUÑOZ MACHADO, S. y REBOLLO PUIG, R. (dirs.): Comentarios al Estatuto de Autonomía de Andalucía, pág. 861. Madrid: Thomson-Civitas.

SALVADOR CRESPO, M. (2014): "Las competencias de las diputaciones provinciales en la Ley 27/2013, de 27 de diciembre, de Racionalización y sostenibilidad de la Administración local”, en Cuadernos de Derecho Local (QDL), núm. 34, pág. 135. URL: https://repositorio.gobiernolocal.es/xmlui/bitstream/handle/10873/1531/10_CRESPO_ P126_144_QDL_34.pdf.

SALVADOTR CRESPO, M. (2019): "El papel de los gobiernos locales intermedios en la actualidad", en Revista Democracia y Gobierno Local, núm. 44, págs. 5-11. URL: https://www.gobiernolocal.org/revista-democracia-ygobierno-local-no-44/.

SÁNCHEZ BLANCO, A. (2006): Organización intermunicipal, págs. 94-99. Madrid: lustel.

SÁNCHEZ MORÓN, M. (2019): Derecho Administrativo. Parte general, pág. 386. Madrid: Tecnos. 15. ${ }^{a}$ ed.

SANTAMARÍA PASTOR, J. A. (2014): "El régimen de competencias locales y el dilema de la esfinge", en SANTAMARÍA PASTOR, J. A. (coord.): La reforma de 2013 del régimen local español, pág. 147. Madrid: Fundación Democracia y Gobierno Local.

VAQUER CABALLERÍA, M. (2012): "Gobiernos locales intermedios y prestación de servicios locales", en Cuadernos de Derecho Local (QDL), núm. 29, págs. 150-153. URL: http://repositorio.gobiernolocal.es/xmlui/ handle/10873/1294.

VELASCO CABALLERO, F. (2011): "La planta local en España: criterios para la toma de decisiones”, en Anuario de Derecho Municipal 2010, núm. 4, pág. 25-54. URL: https://repositorio.uam.es/handle/10486/664365.

VELASCO CABALLERO, F. (2012): "Competencias para la reforma de la planta municipal”, en Cuadernos de Derecho Local (QDL), núm. 29, págs. 62-63. URL: http://repositorio.gobiernolocal.es/xmlui/handle/10873/1289.

VELASCO CABALLERO, F. y VIVER I PI-SUNYER, C. (2012): "Competencias para la reforma de la planta local", en FUNDACIÓN DEMOCRACIA Y GOBIERNO LOCAL: Documento Técnico. Elementos para un debate sobre 
la reforma institucional de la planta local en el Estado autonómico, pág. 152. Madrid: Fundación Democracia y Gobierno Local. URL: https://www.gobiernolocal.org/elementos-para-un-debate-sobre-la-reforma-institucional-dela-planta-local-en-el-estado-autonomico-2/.

ZAFRA VICTOR, M. (2011): "El debate sobre la supresión o reforma de las diputaciones provinciales en España", en Cuadernos de Derecho Local (QDL), núm. 27, pág. 96. URL: http://repositorio.gobiernolocal.es/xmluil handle/10873/1187.

ZAFRA VICTOR, M. (2012): "La intermunicipalidad, modelo de Estado. La provincia en el Estado autonómico", en COSCULLUELA MONTANER, L.; MEDINA ALCOZ, L. (dirs.) y HERNANDO RYDINGS, M. (coord.): Crisis económica y reforma del régimen local, págs. 125-127. Cizur Menor (Navarra): Civitas-Thomson Reuters.

ZAFRA VICTOR, M. (2012): "La provincia: lo importante no es el nombre, lo importante es la función. Intermunicipalidad en el Estado autonómico", en El Cronista del Estado Social y Democrático de Derecho, núm. 27, págs. 68-73.

ZAFRA VICTOR, M. (2012): "Relaciones entre municipios y provincias", en Cuadernos de Derecho Local (QDL), núm. 29, págs. 120. URL: http://repositorio.gobiernolocal.es/xmlui/handle/10873/1293.

ZAMORA ROSELLÓ, M. R. (2013): "La reestructuración de la planta del gobierno local y las mancomunidades de municipios”, en DÍEZ SÁNCHEZ, J. J. (coord.): La planta del Gobierno Local: actas del VIII Congreso de la Asociación Española de Profesores de Derecho Administrativo, pág. 143-144. Alicante, 8 y 9 de febrero de 2013. Madrid: Fundación Democracia y Gobierno Local. 